\title{
BALDAT ULIT: EL ORIGEN DE VALLADOLID A TRAVÉS DE SU TOPÓNIMO
}

\author{
IvÁN PÉREZ MARINAS ${ }^{1}$ \\ Biblioteca Nacional de España
}

Recibido: 20 de enero de 2020

Aceptado: 25 de abril de 2021

\begin{abstract}
Resumen
El topónimo Valladolid ha sido objeto de cierto debate y controversia desde el siglo XIX hasta la actualidad debido a la dificultad de desentrañar su origen y significado. Se exponen los motivos para rechazar la viabilidad de las dos hipótesis más consolidadas, una de fundamentación árabe, Balad Walīd, y otra con elementos latinos y célticos, Vallis Tolitum, y se presenta Baldat Ulit como la alternativa basándose en la documentación más antigua conservada, en las normas de la evolución fonética en las lenguas iberorromances y en el contexto histórico, material y cultural de Valladolid, tanto su zona como el núcleo de población, durante los siglos VIII, IX, X y XI.
\end{abstract}

\section{Palabras clave}

Valladolid; toponimia; siglos VIII-XI; arabización cultural; repoblación

\begin{abstract}
The toponym Valladolid has been subject of debate and controversy from the 19th century to the present due to the difficulty of unraveling its origin and meaning. The reasons for rejecting the viability of the two most consolidated hypotheses, one of Arab derivation, Balad Walid, and another with Latin and Celtic elements, Vallis Tolitum, are explained, and Baldat Ulit is presented as the alternative according to the oldest preserved documentation, the rules of phonetic evolution in the Ibero-Romance languages, and the historical, material and cultural context of the Valladolid, both its area and town, during the 8th, 9th, 10th and 11th centuries.
\end{abstract}

\section{Keywords}

Valladolid; toponyms; 8th-11th centuries; cultural arabization; repopulation

\section{Résumé}

Le toponyme Valladolid a fait l'objet de débats et de controverses du XIXe siècle à nos jours en raison de la difficulté à démêler son origine et sa signification. L'article expose les raisons du rejet de la viabilité des deux hypothèses les plus consolidées, celle de l'origine arabe, Balad Walīd, et celle d'une composition à partir d'éléments latins et celtiques, Vallis Tolitum. L'article présente l'alternative Baldat Ulit en s'appuyant sur la documentation la plus ancienne préservée, les normes d'évolution

\footnotetext{
Biblioteca Nacional de España. Departamento de Manuscritos, Incunables y Raros. Servicio de Manuscritos e Incunables. Madrid. Correo electrónico: ivan.perez@bne.es. OrciD: https://orcid.org/00000002-0055-8886.
} 
phonétique dans les langues ibéro-romanes et le contexte historique, matériel et culturel de Valladolid, à la fois sa zone d'occupation et le noyau de population au cours des VIIIe, IXe, Xe et XIe siècles.

Mots clé

Valladolid; toponymie; VIIIe-XIe siècles; arabisation culturelle; repeuplement

\section{Introducción}

El origen del nombre de Valladolid ha generado cierto debate entre algunos estudiosos de la toponimia y no es un asunto trivial de erudición filológica porque, al fin y al cabo, se está tratando sobre el nacimiento de esta localidad, esto es, el contexto histórico en el que surgió la principal ciudad de Castilla y León. ${ }^{2}$ Esta cuestión aún no ha sido resuelta debido a que parece que ninguna de las hipótesis etimológicas planteadas hasta el momento encaja al completo, al menos en mi opinión y como trataré de demostrar, ya sea por la evolución fonética, ${ }^{3}$ ya sea por el significado del nombre. ${ }^{4}$ Espero haber hallado la solución con una nueva propuesta y esa es la principal razón que me ha llevado a redactar el presente artículo. Así, valoraré y trataré de refutar en primer lugar lo que he dado a calificar como las propuestas populares, surgidas en el siglo XIX y a principios del siglo XX, y a continuación aquellas que tienen fundamento científico, concretamente la de Asín Palacios, que apuntó a Balad Walìd, y la de Montenegro Duque, que defendió que provenía de Vallis Tolitum. Una vez hecho esto expondré el planteamiento que me ha llevado a concluir que el topónimo original debió ser Baldat Ulit y haré un análisis sobre las primeras versiones del gentilicio vallisoletano. Por último, puesto que, como acabo de indicar, tanto o más que el hallazgo del significado del topónimo Valladolid es relevante lo que este trasluce, pretendo ir más allá y haré una presentación de la situación histórica y cultural que debió existir en el momento de la fundación de esta localidad en las tierras de la ribera del Duero y aledaños y cómo esta evolucionó hasta el siglo XII.

\footnotetext{
2 La califico como la "principal" ciudad por lo siguiente: a pesar de estar muy extendido entre la opinión pública, en gran medida porque se estudia así en los colegios, no es cierto que Valladolid sea la capital de Castilla y León, puesto que el Estatuto de Autonomía omite que esta comunidad autónoma tenga capital y ninguna otra ley autonómica lo contempla, y de hecho la propia Junta de Castilla y León ha reconocido que es así en unas declaraciones del 24 de marzo de 2009. Sí se puede considerar que es la más destacada ciudad castellano-leonesa, entre otras cosas, a causa de que es la sede tanto de las Cortes de Castilla y León como de la Junta de Castilla y León (otros órganos autonómicos radican en Burgos, Palencia, León y Zamora).

3 Para la fonética histórica del iberorromance me fundamento en lo establecido por los siguientes manuales: Quilis Morales, Fonética histórica y fonología diacrónica; Medina López, Historia de la lengua española. I, Español medieval; ARIZA VIGUERA, Manual de fonología histórica del español; ARIZA Viguera, Fonología y fonética históricas del español. Asimismo, para la influencia del árabe andalusí en el iberorromance he tenido en cuenta lo marcado en CORRIENTE, Árabe andalusí y lenguas romances.

4 Los significados de las palabras latinas y árabes de esta publicación han sido consultados respectivamente en SEgura Munguía, Nuevo diccionario etimológico latín-español y de las voces derivadas y Corriente, Ferrando y Ould Mohamed Baba, Diccionario avanzado árabe.
} 


\section{Propuestas populares del siglo XIX y principios del siglo $\mathrm{XX}$}

Se han presentado propuestas etimológicas de Valladolid desde el siglo XIX y principios del siglo XX, pero estas no se pueden considerar como verdaderamente "científicas", ya que parecen más las típicas explicaciones folclóricas, populares, que se dan para tratar de zanjar algo cuyo significado no se comprende, incluso a pesar de que fueron defendidas por eruditos de la época. Esto es muy habitual en la toponimia y las recojo para hacer un recorrido histórico completo de todas las que ha habido. Aunque hoy en día pudiera parecer una obviedad que no son propuestas viables hay que tener en cuenta la época en que se realizaron. Así, Matías Sangrador Vítores planteó que Valladolid proviene de vallis oletum o vallis olivetum, ${ }^{5}$ propuesta en la que fue posteriormente apoyado por Andrés Martínez Salazar. ${ }^{6}$ Esto no es posible, en primer lugar, porque hubieran evolucionado fonéticamente hacia otro nombre, algo como Valleoledo; pero además la construcción latina es cuando menos inusual, ya que es la unión de dos sustantivos en nominativo, literalmente en castellano 'valle olivar'. Para que fuera morfológicamente correcto el segundo vocablo debería ser un sustantivo en genitivo plural (oletorum, olivetorum) o un adjetivo en nominativo (olivifer), los cuales fonéticamente tampoco podrían haber evolucionado hasta Valladolid. También se podría plantear que vallis es el genitivo que acompaña al sustantivo en nominativo oletum u olivetum, pero por la toponimia española podemos comprobar que siempre es al contrario, vallis es el elemento principal (por ejemplo, Vallis Sabinorum > Valsaín). Por último, no consta documental ni materialmente que la tierra vallisoletana haya sido prolija alguna vez en el pasado en el cultivo olivarero, sino en cereales (cebada, centeno y trigo), leguminosas, alfalfa, hortalizas, vid, cáñamo y árboles frutales, teniendo por tanto una producción agrícola muy similar a la que hay en la actualidad, que se ha ampliado en los siglos más recientes con cultivos procedentes de América (maíz y patata), junto con la remolacha azucarera, que se implantó desde Europa oriental. También es cuestionable el que se le denomine vallis, pero esto lo trataré más adelante, cuando comente la hipótesis expuesta por Ángel Montenegro Duque.

En un artículo el profesor José María Riguera Montero recogió varias propuestas populares sobre el origen del nombre de la ciudad del Pisuerga, ${ }^{7}$ entre las que mencionó, sin realmente analizarla, la que para mí es la solución correcta, hipótesis que ha pasado desapercibida por los investigadores posteriores y que veremos en su momento. Entre ellas está presente la que acabamos de estudiar, vallis oletum / vallis olivetum, la cual rechaza por la última razón que he esgrimido, la falta de olivares. Sobre la propuesta que defenderé, señaló de forma jocosa que Valladolid podría venir entonces también de Valle de Lid, hipótesis que deambulaba en la época y que César Hernández Alonso descartó unos

\footnotetext{
Sangrador Vítores, Historia de la muy noble y leal ciudad de Valladolid, vol. 1, p. 4 y ss. MARTínez SALAZAR, "Sobre etimologías, Valladolid", pp. 114-120.

Riguera Montero, “¿Vallisoletanos o valisoletanos?”, pp. 129-132.
} 
años más tarde de forma breve. ${ }^{8}$ Pese a ello, su apuesta real fue Vali Soletum y explicó ولي que quiere decir 'residencia del gobernador' basándose en que Vali procede del árabe (walī) y Soletum del diminutivo del término latino solum. Sin embargo, aparte de que no consta documentalmente que en Valladolid residiera un gobernador árabe, ni se testimonia arqueológicamente una vivienda de gran tamaño para fechas anteriores a la dominación leonesa, ${ }^{9}$ resulta un insólito cambio semántico la transformación del significado de solum, que es 'solar', 'casa' o 'residencia'. Además, no se explica cómo la /1/ de Vali se convierte en el fonema $/ K /$, esto es, en la -1l- de Valladolid, ni la /s/ de Soletum en una / $/$ /.

Por último, entre estas hipótesis que he dado en calificar como populares por su escasez de fundamento científico, se encuentra la de Narciso Alonso Cortés, ${ }^{10}$ quien consideró que Valladolid proviene de Vallis Olit, que haría referencia a un valle repleto de una planta, hierba o cultivo indeterminado al que se haría llamar "ulit", "olit" u "olid". Es difícil de admitir esta propuesta, ya que no llega realmente a identificar este término. Es, asimismo, interesante que dedicara casi todo su artículo a tratar de demostrar como falsa la hipótesis que veremos a continuación, en un afán por negar la presencia estable de árabes en las tierras del Duero.

\section{La propuesta de Asín Palacios: Balad Walìd}

A partir de ahora procedo a analizar las dos propuestas sobre el origen del nombre de Valladolid que tienen consistente fundamento científico. Así, en primer lugar, la hipótesis etimológica que planteó Miguel Asín Palacios en 1940 no fue realmente una novedad, ${ }^{11}$ pues había sido previamente postulada por Juan Ortega y Rubio ${ }^{12}$ y mencionada por Alonso Cortés ${ }^{13}$ no obstante, fue el arabista el autor que asentó este planteamiento recogiendo fuentes que lo sustentaran y al que los posteriores investigadores tomaron como referencia para tratar sobre esta hipótesis. En una recopilación de topónimos árabes de núcleos de población de la geografía española Asín Palacios necesitó poco texto para comentar su trabajada propuesta. De este modo citó que se denomina a Valladolid como بلد وليد (Balad Walīd) en una obra del visir granadino Ibn al-Jațīb (1313-1374), concretamente en $A$ 'māal al-a lām, ${ }^{14}$ en la que además se indica que estaba cerca de Simancas, siendo por tanto bastante evidente que hacía referencia a nuestra ciudad, y también señaló otra posible

\footnotetext{
8 Hernández Alonso, Nombre y renombre de Valladolid, p. 6. Es obvio que fonéticamente Valladolid no puede proceder de esta expresión, expresión que, además, está en una forma de lengua romance posterior al momento de los primeros testimonios escritos sobre Valladolid, que son del siglo XI.

9 Palol y Wattenberg, Carta arqueológica de España, Valladolid, pp. 175-206.

10 Alonso Cortés, "En torno a Valladolid".

11 Asín Palacios, Contribución a la toponimia árabe de España, p. 138.

12 Ortega y Rubio, Historia de Valladolid, pp. 27-28 y 35.

13 Alonso CoRTés, "En torno a Valladolid", p. 168. También mencionó una hipótesis muy similar, Balad Wali, que atribuye a Juan Francisco Masdeu, jesuita siciliano del siglo XVIII, pero no indicó dónde fue presentada por este autor.

14 IBN AL-JATīB, Histoire de l'Espagne musulmane, p. 380. Es importante no confundir este libro con otro titulado exactamente igual escrito por Lévi-Provençal y que es un ensayo sobre la historia de al-Andalus.
} 
mención a Valladolid en una obra del egipcio al-Qalqašandī (1355/1356-1418), Subh al-a ‘̌à fi șină at al-inša ${ }^{15},{ }^{15}$ pero no parece que esta identificación sea correcta debido a que esta localidad se ubicaba al oeste de Toledo en vez de al norte. Por último, es de importancia señalar que Asín Palacios tradujo Balad Walìd como 'Pueblo de Walid'.

Esta propuesta, que después retomaron otros autores como Hernández Alonso ${ }^{16}$ y Calvo Baeza, ${ }^{17}$ el primero de forma argumentada y el segundo sin aportar novedades, es un gran avance frente a las anteriores, pues se basa en una fuente documental, y además se acerca bastante a la pronunciación que podría haber tenido en la Edad Media si se compara con la actual. Por lo tanto es aceptable una evolución fonética desde Balad Walīd / balad wali:d/ hasta Valladolid /baKaðolið/, aunque quedaría la duda de cómo el fonema /1/ hubiera llegado a convertirse en el fonema $/ K / .{ }^{18} \mathrm{Sin}$ embargo, el significado del nombre no cuadra completamente, ya que Asín Palacios se equivoca al traducir balad como 'pueblo'. Resulta que 'pueblo' en árabe es قرية (qarya), palabra que por otra parte en nuestra lengua ha derivado en alquería, mientras que balad significa 'país' o 'región' ${ }^{19}$ lo cual no tiene sentido para denominar a un núcleo de población; sí lo tendría, en cambio, para el territorio que circundaba a Valladolid, pero no consta que este fuera su uso en el texto de Ibn al-Jaṭîb, ni en ningún otro medieval. En cuanto al nombre de Walīd me parece totalmente asumible y lo explicaré más adelante al exponer mi hipótesis.

El hecho de que Balad Walìd aparezca documentalmente en la obra de Ibn al-Jațīb me ha hecho reflexionar acerca de dónde surge ese balad y he llegado a la conclusión de que sería la transcripción árabe del nombre romance de Valladolid. Pero antes de exponer los fundamentos de esta deducción, me parece apropiado indicar otras posibilidades que descarté. Así pensé que podría derivar de otra palabra árabe similar, como es (balāt), pero solo una de las dos acepciones de esta palabra puede tener sentido para esta localidad. Una de ellas es 'palacio', que deriva del término latino palatium a través del latín vulgar baletum, y la otra es 'calzada', que proviene del vocablo griego $\pi \lambda \alpha \tau \varepsilon i ́ \alpha$ (plateía) a través del arameo. ${ }^{20}$ No consta que hubiera un palacio o una gran residencia, como ya he mencionado anteriormente, ${ }^{21}$ y lo más parecido que hubo fue el Alcázar Real de Valladolid, construido desde mediados del siglo XII hasta finales del siglo XIII, bien ex novo o bien quizás sobre una torre cuadrada, puesto que la documentación ni la arqueología apuntan a la existencia de una fortificación anterior o un edificio civil

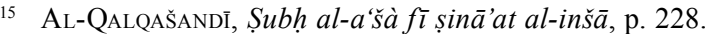

16 Hernández Alonso, Nombre y renombre de Valladolid, pp. 6-11.

17 Calvo Baeza, Nombres de lugar españoles de origen árabe, p. 46.

18 En Hernández Alonso, Nombre y renombre de Valladolid, p. 30, n. 27 se hace referencia a que en Jaime Oliver Asín, En torno a los orígenes de Castilla se explica cómo una palabra fonéticamente similar, balät, puede convertirse en valle, pero tras repasar la obra varias veces no he sido capaz de localizar este pasaje.

19 Al-Balad es el nombre del centro histórico de Yeda, ciudad portuaria de La Meca desde sus orígenes, y se suele traducir como 'La ciudad', pero no se usa como término genérico para cualquier ciudad, por lo que no sería aplicable para el caso de Balad Walīd.

20 Viguera Molins, "La Ruta de la Plata y sus territorios en fuentes textuales árabes"; Franco-Sánchez, "La toponimia árabe de los espacios viales y los espacios defensivos en la Península Ibérica", p. 173.

21 Palol y Wattenberg, Carta arqueológica de España, Valladolid, pp. 175-206.
} 
previo. ${ }^{22}$ En cambio, sí que parece cierto que atravesara una calzada romana por Valladolid. Aunque previas investigaciones habían propuesto que la ruta viaria iba desde Simancas, la romana Septimanca, hacia el nordeste en paralelo al río Pisuerga por el lado norte de esta corriente de agua, ${ }^{23}$ no se han hallado evidencias de la calzada romana en dicha vertiente, frente a muchas evidencias descubiertas en el otro lado, como un miliario en Santovenia de Pisuerga; además, en un documento de 1094 conservado en la catedral de Palencia y en un documento de 1114 conservado en la catedral de Valladolid se mencionan respectivamente una karrera maiore que discurre por medio de la vill $\mathrm{a}^{24}$ y una viam maiorem publicam, ${ }^{25}$ este camino que en la Edad Media comunicaba Valladolid tanto con Simancas como con Cabezón de Pisuerga pasando por Santovenia tuvo que existir desde época romana como calzada. ${ }^{26}$ Por lo tanto, balad podría derivar de balāt, siendo realmente el significado del topónimo 'Calzada de Walīè', si no fuera porque esta hipótesis carece de una explicación fonética para la evolución de $/ 1 /$ a $/ K /$. Así pues, parece lógico pensar que realmente lo que hizo Ibn al-Jațīb fue transcribir en lengua árabe lo mejor que pudo el nombre romance de Valladolid, tal y como se pronunciaba y escribía en el momento en que elaboró su obra, esto es, el siglo XIV: recurrió a una forma posiblemente inspirada en balāt y no al étimo baldat, que es el que, como explicaremos más adelante, da respuesta a los problemas fonéticos que plantea la evolución del topónimo Valladolid. Ibn al-Jațīb eligió una palabra árabe casi homófona de Vallad-, si bien, con la lām, equivalente a nuestra /1/, dado que no hay forma de representar en árabe nuestra $/ K /$. De ahí, los problemas que plantea reconstruir el topónimo a partir de este testimonio. De hecho también Vallvé Bermejo es de esta opinión, ${ }^{27}$ puesto que, según él, todos los topónimos hispanos del A'māl al-a'lām son transcripciones de un texto romance, concretamente de un resumen de la Estoria General de España que le elaboró Yūsuf ibn Waqār (siglo XIV), médico judío y embajador del reino de Castilla. Esta fuente la conocemos gracias a que el propio Ibn al-Jațîb la menciona en su obra.

\section{La propuesta de Montenegro Duque: Vallis Tolitum}

Junto a la hipótesis etimológica de Asín Palacios, la otra propuesta fundamentada científicamente sobre el origen del topónimo Valladolid es la presentada por el filólogo clásico e historiador Ángel Montenegro Duque, que también fue apoyada en líneas generales por Pedro de Palol$^{28}$ y por Celso Almuiña, aunque este recomendaba que se siguiera

\footnotetext{
22 Martín Montes, El Alcázar Real de Valladolid; Martín Montes y Moreda Blanco, “Aproximación a la génesis y desarrollo urbanístico de Valladolid durante la Plena Edad Media (siglos XI-XIII)”, pp. 170 y 177.

23 Fatás Cabeza, Caballero Zoreda, García Merino y Cepas Palanca, Tabula Imperii Romani. Hoja K-30: Madrid. Caesaraugusta-Clunia. El mapa que acompaña como material anejo al libro permite observar fácilmente las rutas de las calzadas romanas.

24 Abajo Martín, Documentación de la catedral de Palencia (1035-1247), doc. 16, pp. 43-47.

25 Castro Toledo, Documentos de la Colegiata de Valladolid, 1084-1300, doc. 19, pp. 53-54.

26 Moreno Gallo, "Vía romana de Sasamón a Villalazán”, p. 19.

27 VAllvé Bermejo, "Toponimia de España y Portugal”, p. 220.

28 Palol y Wattenberg, Carta arqueológica de España, Valladolid, p. 206.
} 
investigando ${ }^{29}$ Ha sido trabajada por Montenegro Duque a lo largo del tiempo en varios artículos, si bien me baso en el último de ellos, debido a que incluyó su planteamiento más elaborado. ${ }^{30}$ Defendía que, cuando se fundó Valladolid entre los siglos VIII y XI, aún pervivía junto a otras poblaciones un sustrato de población celta que fue romanizada y cristianizada por estas fechas. Estas gentes darían un nombre mixto latino y céltico a este nuevo asentamiento y así Valladolid resultaría de la fusión de vallis y tolitum y, por tanto, Vallistolitum, cuyo significado sería 'valle de las aguas'. Por un lado, vallis significaría 'valle', como es obvio. Por su parte, tolitum se conformaría de una raíz céltica, tol-, y del sufijo latino -etum. Tol- estaría presente en otros topónimos de lugar, como Toledo, Villa Tolit, Villoldo y Villotuelda, daría en nuestra lengua las palabras tojo y tollo y al igual que estas querría decir 'tierra pantanosa' o 'lugar de aguas', mientras que -etum habría evolucionado a -itum y serviría para expresar abundancia. ${ }^{31}$ Asimismo, Montenegro Duque incluyó la posibilidad de que la mansio Tela, mencionada en el Itinerario de Antonino (siglo III) y localizada en un punto intermedio entre Intercatia y Pintia, podría ser el precedente de Valladolid tanto en núcleo de población como en topónimo, puesto que tel- es una raíz céltica que tiene relación con el agua en su significado.

Para su estudio utilizó como recurso los testimonios del nombre de Valladolid fechados a finales del siglo XI y a lo largo del siglo XII y que se conservan en el Archivo de la Catedral de Valladolid fundamentalmente, ${ }^{32}$ el Archivo de la Catedral de Palencia, ${ }^{33}$ el Archivo General de Simancas ${ }^{34}$ y el Archivo Histórico Nacional, además de reunir documentos procedentes de los monasterios de San Benito de Sahagún, ${ }^{35}$ Santa María la Real de Aguilar de Campoo, ${ }^{36}$ Santa María de Retuerta, ${ }^{37}$ Santa María de Villanueva de

29 Almuiña Fernández, Personajes vallisoletanos. 6, El nombre de Valladolid.

30 Montenegro Duque, "Origen céltico del nombre y lugar de Valladolid”, pp. 37-56; Montenegro DuQUE, "El origen céltico del nombre de Valladolid y la difusión de la raíz "tol” en la toponimia y hablas hispanas", pp. 29-67; Montenegro DuQue, "El origen céltico del topónimo Valladolid”, pp. 11-37.

31 El significado de -etum es omitido por Montenegro Duque, probablemente por ser de sobra conocido en el ámbito del estudio etimológico y al estar presente, según la postura más extendida desde la publicación de Oliver Asín, Historia del nombre "Madrid”, en el nombre de la capital de España, Madrid, que significaría 'lugar de canales subterráneos'. Sin embargo, para el caso de Madrid, se ha propuesto recientemente un origen bereber para este sufijo en JIMÉNEZ RAYADO, "La construcción de la identidad a través del territorio en la Edad Media". De acuerdo a este estudio, el -it de Madrid provendría del diminutivo bereber que también originaría el diminutivo castellano -ito/-ita y el diminutivo catalán -et y, por tanto, Madrid significaría 'arroyito'.

32 Villalobos y Zurita Nieto, Documentos de la Iglesia Colegial de Santa María la Mayor (hoy Metropolitana) de Valladolid.

33 Fernández del Pulgar, Libro segundo de la historia secular y eclesiástica de la ciudad de Palencia, p. 182. Quizás para su último artículo utilizara Abajo Martín, Documentación de la catedral de Palencia (1035-1247), ya que no indica de dónde tomó todas las fuentes.

34 Paz, "Donación del monasterio de San Cosme y San Damián en Simancas”, pp. 525-526.

35 AHN, Sahagún, Particulares, no 839 y 1035. Fernández Flórez, Colección diplomática del monasterio de Sahagún (857-1300).

36 Tuvo que consultar los originales en el Archivo Histórico Nacional, ya que la edición de estos documentos es posterior a la publicación de su último artículo.

37 Antón, "Monasterio de Retuerta. Documentos". 
Oscos, ${ }^{38}$ Vega,${ }^{39}$ San Román de Entrepeñas ${ }^{40}$ y al parecer también San Zoilo de Carrión de los Condes. ${ }^{41}$ Es significativa la amplia recopilación que realizó entre la documentación medieval, aunque es conveniente advertir que realizó bastantes errores de copia en la transcripción y que anotó mal varias fechas de los documentos. En ellos observó una destacada variedad a causa de la fluctuación fonética que se localizaba precisamente en el supuesto punto de unión de las dos palabras (por ejemplo, Valaolit, Valatoliti, Vallisoleti, Valledoliti, Valleadolito, Valladoliti). Explicó que se debía al contacto de la /s/ y la /t/ y que conllevaría a que -ist- se transformara definitivamente en -ad-.

Ante todo, hay que declarar que la hipótesis de Montenegro Duque está muy bien planteada y cuidadosamente documentada. Sin embargo, contiene muchos elementos que pueden ser sometidos a una crítica exhaustiva. Para empezar, es extraña la posibilidad de que pervivieran sustratos de población celta en una fase tan avanzada de la historia del valle del Duero, sobre todo teniendo en cuenta la reseñable romanización de muchas ciudades y de las áreas rurales de este territorio. De hecho, pudo caer en una contradicción en este sentido cuando finalmente planteó la posibilidad de que una mansio, que evidentemente es romana, fuese el precedente de Valladolid. Además, se conoce desde hace bastante tiempo la existencia de una villa romana en el término municipal vallisoletano, Villa del Prado, excavada por primera vez en $1954 .{ }^{42}$

En cuanto a que Tela fuese el precedente de Valladolid como núcleo poblacional, sería posible, puesto que se han atestiguado restos arqueológicos romanos en el casco urbano vallisoletano, concretamente en la zona de la plaza de la Universidad..$^{43}$ No obstante, no creo que pudiera ser identificada con la villa Villa del Prado porque las mansiones siempre son asentamientos de relevancia. De todos modos, se ha planteado como más plausible la ubicación de Tela en Montealegre de Campos, ${ }^{44}$ por lo que, en consecuencia, es descartable que el nombre de Tela tenga algún paralelismo etimológico con tol-, más aún si tenemos en cuenta que desconocemos si Tela se llamó realmente así, puesto que se ha venido a identificar con otro lugar llamado $\Gamma \dot{\lambda} \lambda \lambda \alpha$ (Gélla) por Ptolomeo (ca. 100-ca. 170) y llamado Gela en el Anónimo de Rávena (siglo VII). ${ }^{45}$

\footnotetext{
38 AHN, Sección de clero, Villanueva de Oscos, carp. 1616, n 16. Floriano Llorente, "Colección diplomática del monasterio de Villanueva de Oscos. Primera serie: (años 1136-1200)".

39 Serrano, Cartulario de monasterio de Vega con documentos de San Pelayo y Vega de Oviedo.

40 AHN, San Román de Entrepeñas, n ${ }^{\circ} 16$ bis.

41 Desconozco la procedencia de las fuentes consultadas por Montenegro Duque que procediesen de este monasterio, ya que, en la edición más reciente de la colección diplomática de San Zoilo de Carrión, Palacio Sánchez-Izquierdo, Colección diplomática del monasterio de S. Zoilo de Carrión (siglos IX al $X V)$, la mención más antigua de Valladolid que he localizado es de un documento de $1220 \mathrm{y}$, por tanto, fuera de su rango temporal de análisis.

42 Palol y Wattenberg, Carta arqueológica de España, Valladolid, pp. 175-206.

43 Martín Montes y Moreda Blanco, "Aproximación a la génesis y desarrollo urbanístico de Valladolid durante la Plena Edad Media (siglos XI-XIII)", p. 163.

44 Fatás Cabeza, Caballero Zoreda, García Merino y Cepas Palanca, Tabula Imperii Romani. Hoja K-30: Madrid. Caesaraugusta-Clunia, p. 122.

45 Ibidem.
} 
En cuanto a los dos términos que componen Vallistolitum, nos centraremos en primer lugar en vallis. La propuesta de que Valladolid haga referencia a un valle viene al menos del siglo XIX, o, al menos, esta es la época más antigua que hemos podido constatarlo, y se ha repetido constantemente en varias hipótesis sin que nadie la haya rebatido, puesto que para su refutación se limitaban a la palabra que acompañaba a ese supuesto valle. Con esto presente, resulta llamativo que nadie se haya percatado de que Valladolid no está localizado en un valle, sino en una llanura rodeada de cerros testigo entre los ríos Esgueva y Pisuerga, cerca de su desembocadura en el río Duero. Ciertamente se encuentra dentro de un valle, mucho más amplio, el del Pisuerga o del Esgueva, pero debido a la inmensidad territorial de ambos es poco razonable que se estuvieran refiriendo a uno de ellos en el topónimo Valladolid; y en todo caso se hubiera denominado más bien algo así como Valpisuerga o Valesgueva.

Sobre tolitum, aparte de que es posible que la raíz tol- no sea céltica sino "preceltibérica” en opinión de Ramón Menéndez Pidal, ${ }^{46}$ desarrollada y apuntalada posteriormente por autores como Antonio Tovar, Jürgen Unterman, Francisco Villar Liébana, Martín Almagro-Gorbea y Edelmiro Bascuas López, ${ }^{47}$ normalmente los topónimos prerromanos que pervivieron durante las épocas romana y visigoda en la cuenca del Duero pertenecen a núcleos de población que fueron fundados antes de la ocupación romana (por ejemplo, Segovia, Salamanca, Osma, Roa, Simancas, Briviesca, etc.). No es habitual que pueda existir asentamiento humano con un topónimo en la lengua de una cultura de época anterior a su fundación y, generalmente, sería al contrario, que cambiara de denominación a la lengua de una cultura posterior; así, como tendencia generalizada, los poblamientos con topónimo latino fueron creados en época romana (León), aquellos con topónimo germánico surgieron en época visigoda (Águilafuente) y los que presentan un topónimo árabe o bereber aparecieron en los siglos VIII-XI (Alcazarén, Majuges). ${ }^{48}$ Aun admitiendo la posibilidad de que hubiera pervivido desde época prerromana, lo fundamental es que la evolución fonética no sustenta la etimología Vallistolitum. Como bien ha señalado Hernández Alonso, ${ }^{49}$ es normal que la /t/ inicial dentro de Vallistolitum, al ser un fonema sordo intervocálico, se transforme en /ð/, pero no se conocen casos de evolución fonética en que desaparezca, tal y como se ve en algunas de las variantes escritas de Valladolid atestiguadas en el siglo XI, esto es, en las más antiguas (Valleolit, 1084; Valaolit, 1088). Es más, añadiría que no es habitual que una terminación -is de vallis o -em de vallem, tanto si hubiera evolucionado a partir del caso nominativo

\footnotetext{
46 MenÉndez PidAl, "Sobre el sustrato mediterráneo occidental".

47 Tovar, "El nombre de celtas"; Untermann, Elementos de un atlas antroponímico de la Hispania antigua; Villar LiÉBANA, "Las vocales /o/ y /u/ de la toponimia prerromana hispana"; ViLLAR LiÉBANA, "Talabara, Talavera, Toledo"; Almagro-GorbeA, "Los orígenes de Toletum y su topónimo campaniforme"; Bascuas López, Hidronimia y léxico de origen paleoeuropeo en Galicia. Sirvan estas obras como una breve selección de los muchos estudios de estos autores sobre este tema.

48 Véase una recopilación de topónimos de asentamientos anteriores al siglo XII de la vertiente meridional del valle del Duero, en los que se indica su procedencia, en Iván PÉrEz Marinas, Tierra de nadie, pp. 230-348.

49 Hernández Alonso, Nombre y renombre de Valladolid, p. 8.
} 
como si lo hubiera hecho a partir del caso acusativo, se hubiera convertido finalmente en /a/ por el hecho de estar en contacto con la /t/ inicial de tolitum. Por último, si $\mathrm{Va}$ lladolid procediera de tolitum, en los textos de los siglos XI y XII, aparte de aparecer terminando en $-i$, esto es, en genitivo, ${ }^{50}$ tendría que aparecer habitualmente en $-u m$, en nominativo y acusativo, y en - $o$, en dativo y ablativo, algo que ocurre muy escasamente (véase Anexo I).

\section{Mi propuesta: Baldat Ulit}

Una vez descartadas las dos hipótesis existentes procedo a presentar y explicar una nueva propuesta que pretende dar solución a los problemas aún no bien resueltos. El topónimo Valladolid está conformado por la unión de dos palabras: baldat, que procede del árabe بلدة y significa 'villa', y Ulit, que es la versión romance del antropónimo árabe وليد (Walīd). Por lo tanto, Valladolid es 'la villa de Walīd'.

Para llegar a esta deducción he analizado, al igual que Montenegro Duque, ${ }^{51}$ el conjunto de testimonios del topónimo Valladolid fechados en los siglos XI y XII que están presentes en los documentos procedentes de la Colegiata de Santa María de Valladolid, ${ }^{52}$ el Archivo General de Simancas, ${ }^{53}$ la catedral de Palencia ${ }^{54}$ y los monasterios de San Benito de Sahagún, ${ }^{55}$ Santa María la Real de Aguilar de Campoo, ${ }^{56}$ Santa María de Retuerta $^{57}$, Vega ${ }^{58}$ San Pelayo de Oviedo, ${ }^{59}$ San Román de Entrepeñas ${ }^{60}$ y Santa María de Villanueva de Oscos, ${ }^{61}$ ya que son los más antiguos conservados con menciones a Valladolid e incluso muchos de ellos fueron redactados en la propia localidad. Se pueden ver en el Anexo I. Es importante tener en cuenta que estos topónimos pueden contener errores de copia, ocurridos tanto en la elaboración medieval de los documentos como en la redacción reciente de sus ediciones, y que muchos de ellos están versionados al latín, por lo que presentan una deformación respecto al original romance. Así vemos

\footnotetext{
50 No siempre que el nombre de Valladolid terminando en $-i$ está en genitivo, puesto que también aparece así estando en acusativo y ablativo (véase Anexo I). Más adelante explico el motivo.

51 Montenegro Duque, "El origen céltico del topónimo Valladolid", pp. 18-22. He corregido sus errores de copia en la transcripción y las fechas que he detectado al cotejar su listado con los documentos, tanto en las ediciones que él utilizó como en las nuevas ediciones, y he ampliado las menciones de Valladolid halladas utilizando sus mismas fuentes.

52 Castro Toledo, Documentos de la Colegiata de Valladolid, 1084-1300.

53 Castro Toledo, Documentos de la Colegiata de Valladolid, 1084-1300, doc. 19. Se conserva en AGS, Consejo Real, 105-8, pieza II, hojas 63-64.

54 Abajo Martín, Documentación de la catedral de Palencia (1035-1247).

55 Fernández Flórez, Colección diplomática del monasterio de Sahagún (857-1300).

56 Rodríguez de Diego, Colección diplomática de Santa Maria de Aguilar de Campoo (852-1230).

57 Antón, "Monasterio de Retuerta. Documentos".

58 Serrano, Cartulario de monasterio de Vega con documentos de San Pelayo y Vega de Oviedo.

59 Ibidem

${ }^{60}$ AHN, San Román de Entrepeñas, $\mathrm{n}^{\circ} 16$ bis.

61 Floriano Llorente, "Colección diplomática del monasterio de Villanueva de Oscos. Primera serie: (años 1136-1200)”, pp. 135-136.
} 
como estos topónimos latinos aparecen declinados en genitivo o ablativo y adoptan la forma inicial de vallis en una recreación cultista al latín, a causa de identificar la forma romance valle, proveniente en este caso de la evolución fonética de baldat, como un poco más adelante veremos, con un valle propiamente dicho debido a la homonimia. Afortunadamente bastantes de ellos mantienen su escritura romance, sobre todo aquellos anteriores a mediados del siglo XII, puesto que a partir de entonces se convirtió en costumbre escribir su versión latinizada.

Teniendo esto presente podemos determinar que el primer componente de los dos que conforman Valladolid oscila entre Vala, Balad, Valad, Valat, Val de, Valde, Valded, Valed, Valid, Vallad, Vallas, Valle, Vallead, Valled, Valle de, Vallem, Valles, Vallis y Valt. ${ }^{2}$ Salvo las recreaciones cultistas latinas (Uallis y sus variantes, quizás errores de copia, Uallas y Ualles), considero que son evoluciones fonéticas de una misma palabra árabe,بلدة. Esta palabra significa 'villa', en el sentido de un núcleo de población intermedio entre un pueblo y una aldea. Debido a que, por ser de género femenino, termina con la letra tā' marbūța, se pronuncia de dos maneras, /balda/ y /baldat/, dependiendo respectivamente de si esta palabra va aislada o de si la palabra que la acompaña tiene una relación de posesión hacia ella (iḍāfa), como es el caso que nos ocupa. Sin embargo, aunque mencionaban la /t/ o, en su lugar, una /ð/ como sonorización de /t/, no siempre respetaban la pronunciación esperada, puesto que la articulaban como si fuera una palabra aislada; por eso en ocasiones no aparece una consonante al final. También a causa de la iḍāa la palabra principal se determina y, por tanto, su traducción debe llevar artículo, 'la villa'. Esta /t/, al pronunciarse de continuo con el siguiente componente, Ulit, en una posición intervocálica, se sonorizó en /ð/ como evolución fonética, resolviéndose así uno de los puntos más débilmente explicados en las hipótesis formuladas hasta ahora. Junto a esto, a pesar de que en el árabe de Próximo Oriente las dos vocales de esta palabra se pronuncian /a/, hoy en día en el dialecto árabe de Marruecos, Argelia y Túnez se pronuncian /æ/, debido a que van acompañadas de consonantes que no son faringalizadas, uvulares, glotales, velares o faringales. ${ }^{63}$ Era de igual modo en el árabe andalusí, ya que a causa de esto palabras de nuestra lengua que proceden del árabe están presentes con una /e/ posconsonántica como evolución fonética de /æ/ (masŷid $>$ mezquita; madinna > medina; al-zayt $>$ aceite). Así pues, nos encontramos que los habitantes del valle del Duero de la Alta Edad Media pronunciaban originalmente en árabe tanto /bældæ/ como /bældæt/. En las distintas variantes toponímicas recogidas de Valladolid, la primera /æ/ había evolucionado a /a/, a diferencia de la segunda /æ/, que oscilaba entre /a/ y /e/, quedando posterior y definitivamente también como /a/.

En iberorromance medieval la 'b' y la ' $v$ ' se pronunciaban de forma distinta: /b/ correspondía a la 'b', mientras que para la ' $v$ ' era $/ \beta / \mathrm{o} / \mathrm{v} /$, puesto que su fonema no se sabe

\footnotetext{
62 Aclaro que el hecho de que la primera letra pueda aparecer como U o como V es una mera cuestión gráfica; están representando la misma letra. Sin embargo, en el iberromance medieval sí que hay una diferencia entre escribir B y U/V, puesto que se pronunciaban diferente, como explicaré un poco más adelante.

63 Moscoso García, Esbozo gramatical del árabe marroquí, pp. 33-34.
} 
exactamente con certeza. ${ }^{64}$ Sin embargo, esto no era así cuando la v se encontraba detrás de un sonido nasal o en inicio de palabra, pronunciándose igual que la ' $b$ ', esto es, /b/; de ahí la confusión entre una letra y otra en baldat. Por último, el grupo consonántico -ld- unas veces se mantuvo, unas pocas veces se simplificó en -l- y la mayoría de las veces se convirtió en -1l-, pronunciado como doble ele o como $/ K /$, que es la forma que pervivió finalmente. Aunque no podría descartarse completamente una evolución directa de -ld- a $/ K /$, lo que seguramente ocurrió fue una identificación del inicio de la palabra con valle, al igual que con su apócope habitual en lengua romance seguido de preposición, val(de), como ocurre en Valsaín (Vallis Sabinorum), Valpuesta (Vallis Posita), Valbuena (Vallis Bona $)^{65}$ y Valdecañas de Tajo, entre muchos otros; de ahí que aparezcan intermitentemente vall- y val- en la documentación.

Es posible que, al menos en parte de la población, el significado original de 'la villa' se olvidara a partir del siglo XI a causa de la implantación de la cultura latina de los territorios septentrionales hispánicos frente a la cultura árabe andalusí. Esto explicaría la mencionada confusión con un valle propiamente dicho y su latinización en vallis.

En cuanto a la segunda palabra del topónimo original, vemos que en los testimonios recogidos aparece de las siguientes maneras: oleti, oleto, oletum, olid, olide, olidi, olido, olio, olit, olite, olite, oliti, olith, olithi, olito y olliti. Me he decantado por Ulit, la forma romance del árabe Walīd, y no de la forma primigenia árabe porque al acabar algunas de estas variantes romances en / $\mathrm{t} /$ nunca habrían podido evolucionar del fonema /d/ árabe, pero sí de una forma romanceada en -t podría llegarse a las variantes plenamente romances en -d. Este nombre árabe romanceado se encuentra en crónicas latinas hispanas de los siglos IX-XIII para referirse a Al-Walīd ibn 'Abd al-Malik, califa de Damasco del año 705 al 715 y gobernante de los árabes durante la conquista de Hispania, por lo que me lleva a pensar que sería esta su forma común y no la árabe. Así, se puede leer "regnante in Africa Ulith Amir Almauminin filio de Abdelmelic" en la Crónica albeldense (881-883) ${ }^{66}$ y "Hulit, fortissimus rex barbarorum totius Africe" en la Historia legionense (ca. 1110-1125; tradicionalmente conocida como Historia silense) ${ }^{67} \mathrm{y}$, también, debido a que su autor copió el pasaje de esta crónica, en el Chronicon mundi de Lucas de Tuy (década del 1230). ${ }^{68}$ Asimismo, aparece otro personaje llamado Ulit Habulhabaz, esto es, Walīd Abū al-'Abbās, en la batalla de San Esteban de Gormaz (917) narrada en la Historia silense, ${ }^{69}$ si bien, aunque esto no afecta a nuestro análisis, según las crónicas árabes realmente era Abū al-‘Abbās Aḥmad, caíd del Emirato de Córdoba. ${ }^{70}$

\footnotetext{
${ }^{64}$ Alonso García, "La 'b' y la 'v"”; Alonso y Fernández de las Redondas, "B = V en la Península Hispánica".

65 Como se comprueba en estos dos topónimos, originalmente vallis era un sustantivo de género femenino.

66 Gil Fernández, Crónicas asturianas, pp. 182-183.

67 Historia silense, pp. 127-128.

68 LuCAS DE TuY, Chronicon Mundi, p. 220.

69 Historia silense, pp. 157-158.

70 Una crónica anónima de Abd al-Rahman III al-Nasir, pp. 123-124; IBN HaYYȲN, Crónica del califa Abderramán III an-Násir entre los años 912 y 942 (Al-Muqtabis V), p. 111; IBN 'IDARI, Histoire de l'Afrique et de l'Espagne intitulée Al Bayano'l-Mogrib, vol. 2, p. 283.
} 
Además, este antropónimo romance, ya evolucionado a Olit, junto con su variante Oliti, aparece en documentos de los siglos IX-XI de territorios bajo dominio cristiano, concretamente en varios de los Tumbos del monasterio de Sobrado de los Monjes, ${ }^{71}$ en un documento asturiano del año 874, ${ }^{72}$ en uno portugués del año 946 recogido en los Portugaliae Monumenta Historica ${ }^{73}$ y en uno gallego de la misma época. ${ }^{74}$ Incluso se presenta como apellido, Olidiz, en un documento del 1045 que fue copiado en el Libro del tumbo del Archivo de la Catedral de León (finales del siglo XII). ${ }^{75}$ Este conjunto de nombres es recogido por Montenegro Duque, con ciertos errores tanto de copia en la transcripción como de paginación de las fuentes, para precisamente rechazar que Walīd no existía como antropónimo árabe en España, cuando en mi opinión precisamente lo demuestra y además evidencia que estaba extendido en territorio cristiano. ${ }^{76} \mathrm{Sin}$ embargo, lo más interesante es que un presbítero llamado Holit consta en Simancas en el año 927 como uno de los testigos de la carta de donación del obispo Cixila de León, comúnmente conocida como Testamento de Cixila, quedando así demostrado que este nombre existía en las inmediaciones de Valladolid. ${ }^{77}$

Del étimo Ulit la primera vocal se cierra en /o/, al igual que en ocasiones la segunda vocal en /e/ aunque esta forma no perduró a la actualidad. Se observa que en alguno de los topónimos la ' 1 ' se duplica, quizás pronunciándose como doble 'l' en vez de como / $\mathrm{K} /$ o quizás sencillamente como una alternancia gráfica que no respondía a la pronunciación real, pero es muy inusual y no se ha conservado en la forma actual. La terminación en -t derivó a variantes con la terminación -th, que se pronunciaría igualmente como /t/ o quizás, por dificultad de su pronunciación en su posición final, correspondería al fonema $/ \theta /$, y sobre todo al acompañamiento de las vocales /e/ e /i/. Sin embargo, en algunos de los topónimos estas vocales finales pudieron deberse a su declinación en caso genitivo (segunda declinación) o ablativo (tercera declinación) a causa de su recreada versión cultista en latín, al igual que las otras terminaciones declinativas en -ę, -um y -o. Por último, esta /t/ final sonorizó en /ð/, tal y como está presente en algunos de los topónimos recopilados, aunque también pudo pronunciarse con una vocal /e/ paragógica, como apoyo, para facilitar su sonorización, ${ }^{78}$ lo que también podría explicar la terminación vocálica atestiguada en la documentación a la que me acabo de referir. La gran duda es quién fue este Walīd. Evidentemente sería muy venturoso llegar a afirmar que el nombre de esta villa fue dedicado en honor al califa al-Walīd o al su-

\footnotetext{
71 Loscertales García de Valdeavellano, Tumbos del Monasterio de Sobrado de los Monjes, pp. 69, 95 y 169.

72 Floriano, Diplomática española del periodo astur, vol. 2, p. 97.

73 Herculano, Portugaliae Monumenta Historica. Diplomata et Chartae, fasc. 1, doc. LVI, pp. 32-33.

74 SÁnchez-ALbornoz, La España cristiana de los siglos VIII al XI, vol. 1, p. 207.

75 Libro del tumbo, f. 192.

76 Montenegro Duque, "El origen céltico del topónimo Valladolid”, pp. 17-18. Consideraba que es un antropónimo originalmente romance que procede de olivetum.

77 SÁez SÁnchez, Colección documental del Archivo de la Catedral de León (775-1230), vol. 1, doc. 75.

78 Esto ocurre en otros topónimos originalmente terminados en -t que evolucionaron a -d, como es el caso de Madrid.
} 
puesto caudillo militar andalusí Walīd Abū al-'Abbās o que tuviera alguna relación con el presbítero simanquino. En el pasado la posibilidad de que el origen de Valladolid estuviera relacionado con un personaje árabe fue rechazada de forma más o menos beligerante. Así, Alonso Cortés negó tajantemente que pudiera haber árabes en Valladolid porque según él tan solo estaban presentes en el valle del Duero para depredar y nunca pasaron por esta localidad. ${ }^{79}$ Por su parte, como acabamos de comprobar, Montenegro Duque consideraba que este nombre ni siquiera existía en la región y que los que había en otros territorios cristianos no procedían del árabe sino del romance olivetum ${ }^{80} \mathrm{Sin}$ embargo, resulta llamativa la existencia de leyendas sobre un "moro" Walīd en la ciudad del Pisuerga. Así, autores como García Alonso de Torres en su Espejo de la nobleza (ca. 1500), ${ }^{81}$ Gonzalo de Arredondo en su Historia del conde Fernán González ${ }^{82}$ Julián del Castillo en su Historia de los reyes godos $(1582)^{83}$ y Juan Antolínez de Burgos en su Historia de Valladolid $(1644)^{84}$ narraban los siguientes supuestos sucesos históricos: un capitán llamado Ulit, que había sido uno de los conquistadores del Reino visigodo, reconstruyó la antigua ciudad de Pintia tras haber sido destruida por ellos dándole el nombre de Valladolid; el rey asturiano Alfonso III se alió con un sucesor de nombre también Ulit para tomar el castillo del legendario Bernardo del Carpio; el Ulit derrotado por el rey leonés Ordoño II en la anteriormente mencionada batalla de San Esteban de Gormaz era en realidad otro señor de Valladolid; el conde castellano Fernán González luchó y derrotó a otro descendiente suyo llamado Ulit en Valladolid; el rey leonés Ramiro II venció y mató a un rey moro Ulit en la batalla de Simancas; e incluso el rey leonés Alfonso VI derrotó y decapitó al rey moro Ulit en Valladolid. La credibilidad histórica de estos relatos es por supuesto nula, pero es sintomático que se pensara que los orígenes de esta ciudad estuvieron vinculados con un musulmán y asumieran que el nombre de Valladolid derivara de Walīd.

Junto a estas historias, desde mediados del siglo XII en la plaza que se encontraba ante la desaparecida iglesia de Santa María la Antigua de Valladolid, se erigía un rollo de piedra sobre el que se encontraba un león que portaba un estandarte con el escudo de armas de Pedro Ansúrez y tenía a sus pies lo que parece la cabeza decapitada de un hombre con aspecto cultural árabe, que simbolizaba la dominación de Valladolid por parte del reino de León a través de Pedro Ansúrez, primer señor de Valladolid, frente a su antiguo gobernante. De hecho, debajo tenía una inscripción latina que rezaba "Ulit oppidi conditor" ('Walīd, fundador de esta ciudad'). ${ }^{85}$ Este monumento fue trasladado en el siglo XVI al atrio de la catedral de Valladolid, donde fue destruido en 1841 a causa del derrumbe de una de las torres de este edificio, ${ }^{86}$ pero afortunadamente se conserva un dibujo realizado

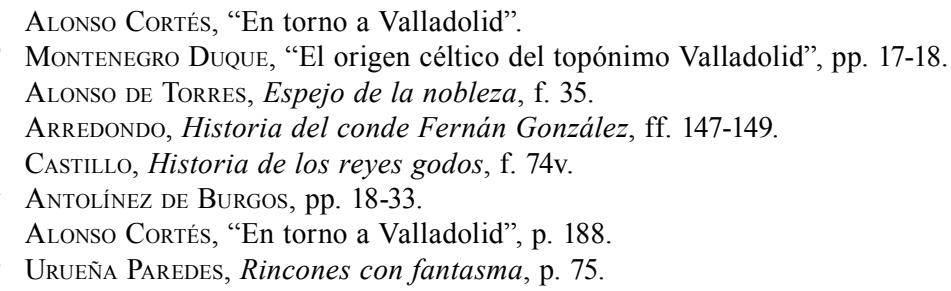


por Ventura Pérez en el siglo XVII que lo representa. ${ }^{87}$ De nuevo vemos cómo pervivió el recuerdo de cierto Ulit como señor e incluso fundador de Valladolid. En mi opinión, considerando lo habitual que es en la época medieval denominar un asentamiento con el nombre de la persona que lo fundó, lo más probable es que Ulit fuera un rico propietario de tierras, con una importante impronta cultural árabe, teniendo en cuenta su nombre, y que podría haber sido tanto un cristiano como un musulmán, dado que este antropónimo era común tanto en líderes árabes como en civiles y religiosos del reino de León. Volveré sobre este asunto en las conclusiones del presente artículo.

Curiosamente mi hipótesis de étimo, Baldat Ulit, apareció muy sucintamente referida en el estudio de Riguera Montero con una variante de la evolución fonética de la primera palabra, velda: "nos cuentan antiguos filólogos que Valladolid se deriva de Velda o Velad (tierra) y de un moro Ulid, Ulit o Ulete" ${ }^{88}$ Este autor la rechazó sin dar argumentos y es una lástima que no indicara quiénes fueron esos filólogos que llegaron a mi misma deducción.

Es importante destacar que el nombre árabe de Valladolid no es un hecho aislado, puesto que no es el único núcleo de población que también tendría este origen etimológico, ya que en Galicia existen tres aldeas llamadas Valdolide. Actualmente con menos de una veintena de habitantes cada una, se encuentran en los municipios de Touro ( $\mathrm{La}$ Coruña), Vilar de Astrés (Orense) y Pobra de Brollón (Lugo). He tratado de buscar información sobre la historia de estos tres lugares, pero no he sido capaz de hallarla. Aun así, pienso que cabrían dos opciones sobre sus orígenes. En primer lugar, habría otras personas llamadas Ulit que dieron lugar a estos asentamientos en Galicia, ya que, como hemos tratado y veremos adelante todavía más, los antropónimos de procedencia árabe estaban presentes en el cuadrante noroccidental de la Península Ibérica en los siglos VIII-XI, e incluso sus fundaciones podrían estar relacionadas con la llegada a Galicia del caudillo andalusí, bereber y musulmán Maḥmūd ibn 'Abd al-Ŷabbār (muerto en el 840 d.C.) para luchar a las órdenes del rey asturiano Alfonso II, tal y como se narra en la Crónica albeldense (terminada en el año 881) y más detalladamente en Al-Muqtabis de Ibn Ḥayyān (987-1075). ${ }^{89}$ En segundo lugar, en un momento intermedio durante el proceso de evolución fonética, esto es, entre los siglos VIII y XI, pobladores del Valladolid del Pisuerga podrían haber emigrado hasta Galicia, haberse dispersado en varios

87 Pérez, Historia de la muy noble y muy leal ciudad de Valladolid, vol. 1, f. 33r. Se puede ver en línea en la Biblioteca Digital Hispánica.

88 Riguera Montero, “¿Vallisoletanos o valisoletanos?”, p. 130.

89 Gil Fernández, Crónicas asturianas, p. 175; Ibn Ḥayyān, Crónica de los emires Alhakam I y 'Abdarrahmān II entre los años 796 y 847 (Almuqtabis II-I), p. 298 y ss. Sobre este caudillo, léase AgUIRRE CAno, "Mahmud ben Abd al-Yabbar". Además, Mahmūd fue acompañado de su hermana Ŷamīla ibn 'Abd al-Ŷabbār, caudilla que dirigía una unidad militar conformada exclusivamente por mujeres guerreras en las batallas que lidiaba su hermano. A la muerte de este, fue cristianizada y casada con un noble, con quien tuvo descendencia. Sobre este interesantísimo personaje, recomiendo la lectura de Viguera Molins, "Una andalusí en Galicia y sus cuatro "transgresiones". Posiblemente muchos otros bereberes arabizados que les acompañaron, tanto hombres como mujeres, se quedaran en tierras gallegas, probablemente cristianizados, y mantuvieran parte de su cultura, entre la que estaría la antroponimia familiar en lengua árabe. 
puntos de esta tierra y haber fundado las tres aldeas poniendo el nombre de su lugar de procedencia. En todo caso, el transcurso desde Baldat Ulit hasta Valdolide presenta elementos comunes con el que dio lugar a Valladolid. Así, se utilizó indistintamente las grafías B y V por su idéntica pronunciación como /b/ al inicio de palabra, se produjo una apócope con val(de) por su confusión con valle, todas las $/ \mathrm{t} /$ sonorizaron en $/ \mathrm{d} / \mathrm{y}$, por último, la /u/ se abrió en /o/. En cambio, en su evolución hacia el romance gallego se diferenció en dos elementos: la apócope val(de) provocó la fusión de las dos palatales de Baldat, haciendo desaparecer la "a" intermedia, y se mantuvo la vocal /e/ paragógica final, que, como apoyo, facilitó la sonorización de la -t final.

Además, es significativo que haya más topónimos árabes en las inmediaciones de Valladolid (Alkamin, ${ }^{90}$ San Cebrián de Mazote, ${ }^{91}$ Alcazarén,,${ }^{92}$ Villalbarba, ${ }^{93}$ Zaratán, ${ }^{94}$ etc.) y también que haya otros asentamientos en España que comparten el primer elemento de su nombre. Así, aparte de los Valdolide mencionados, de بلدة (balda) encontramos Albelda, tanto la localidad riojana como la oscense, que tienen la palabra árabe con su artículo delante y por lo tanto significan 'la villa'. ${ }^{95}$ Además, me planteo la remota posibilidad de que no todos los topónimos que empiezan por valde- hagan referencia a un valle mediante la apócope val seguida de la preposición de, ya que, como hemos observado en la ubicación de Valladolid, tampoco se sitúan en un valle sino en el llano o en un cerro. De esta manera podemos mencionar como casos más posibles aquellas localidades que estén compuestas por valde- y un antropónimo, como quizás Valdeande (Burgos), que podría proceder de Fernande, Valdesantiago (Salamanca), Valdejimena (Salamanca) o Valderrodrigo (Salamanca). Exactamente igual ocurriría con algunos de los topónimos actuales que empiezan con valle-, siendo bastante probable el caso de Vallecas, antiguo municipio que desde 1950 está integrado en la ciudad de Madrid, ya que en el Fuero de Madrid (1202) aparece mencionado como Balecas. ${ }^{96}$ De ser así Vallecas procedería de بلدة قسي (Balda Qasī) y significaría 'la villa de Casio'. Como vemos en muchos de estos topónimos, el antropónimo que acompaña a balda no es árabe, por lo que de ser cierta esta hipótesis valde se utilizó brevemente en lengua romance, al igual que medina, para designar núcleos de población. Por último, de balda seguramente también provengan los apellidos Balda y Belda.

\footnotetext{
90 Alkamín proviene de al-kamin ('el horno' o 'la chimenea'). CASTro Toledo, Alkamin: un lugar en la Tierra de Tordesillas.

${ }^{91}$ Mazote proviene de mas'ūd ('beato’) según Oliver Asín, En torno a los orígenes de Castilla, p. 18, pero también es un antropónimo árabe.

${ }^{2}$ Alcazarén proviene de al-qașrayn ('los dos castillos') según Oliver Asín, En torno a los orígenes de Castilla, p. 44.

93 Villalbarba proviene de villa al-barbar ('villa de los bereberes') de acuerdo con lo que expone OLIVER Asín, En torno a los orígenes de Castilla, pp. 24-25.

94 Zaratán proviene de saratān ('cangrejo de río' o ‘cordelería') según CELDRÁn, Diccionario de topónimos españoles y sus gentilicios, p. 900 y Moro Gutiérrez, “Estudio etnográfico de Zaratán”, p. 204.

95 Asín Palacios, Contribución a la toponimia árabe de España, pp. 47-48.

96 El Fuero de Madrid, p. 207.
} 
En cuanto a coincidencias del segundo elemento de Valladolid, Ulit, en otros topónimos es de sobra conocido el debate al respecto sobre si el nombre de la localidad navarra de Olite proviene de este antropónimo árabe. Me parece muy plausible teniendo en cuenta que las referencias más antiguas a Olite sean muy similares a las de Valladolid: Olit (1102), Holeti (1102), Olith (1171), Olete (1234), Oletus (1253), Oleti (1280), Oleto (1280), Holit (1280), Olite (1312) y Olitus (1396). ${ }^{97}$

\section{Los gentilicios de Valladolid: baladolense, valleoletano/a, vallisoletano/a y va- llisoletense}

Relacionado con el topónimo Valladolid otra cuestión a analizar es su gentilicio. Actualmente el gentilicio procede de la versión cultista latinizada del topónimo Valladolid, que como consta en los documentos de los siglos XI y XII estudiados es Vallisolit. Sin embargo, en esta misma documentación, procedente del Archivo de la Catedral de Valladolid ${ }^{98}$ y del Archivo de la Catedral de Palencia, ${ }^{99}$ se detectan cuatro gentilicios de Valladolid: baladolense, valleoletano/a, vallisoletano/a y vallisoletense. Están recogidos en el Anexo II y se deben a las tres de las cuatro principales variantes que tenía el topónimo Valladolid en esa época: Valadolit/Valaolit, Valleolit/Valleolet y Vallisolit. De la cuarta variante, Valladolid, que es la que ha pervivido hasta la actualidad, no hemos localizado su correspondiente gentilicio, entre otras cosas porque los gentilicios no abundan en la documentación, sino más bien todo lo contrario.

En primer lugar, observamos el gentilicio más antiguo, baladolense / baladonense, en un grupo de cuatro documentos de los años 1110, 1114 y 1115; concretamente los tres últimos tratan sobre un mismo asunto de donación de heredades a la iglesia de Santa María de Valladolid por parte del conde Pedro Ansúrez y todos ellos fueron redactados por el mismo escribano, Martín. Pienso que por su mayor parecido al topónimo la diferencia de las dos variantes, esto es, el trueque de un fonema nasal, se debió a un error de copia del manuscrito y no a una alteración fonética, siendo por tanto baladolense la forma correcta. A su vez baladolense debe contener una contracción, ahora sí por evolución del gentilicio, a partir de baladolitense, palabra que tiene que derivar de *baldatolitense si seguimos la misma transformación fonética que indicamos previamente para el topónimo.

En segundo lugar, tenemos valleoletano/a, que aparece declinado en latín en primera y segunda declinación para los géneros femenino y masculino respectivamente en documentos de finales del siglo XII. Este gentilicio se conformó a partir de la variante del topónimo Valleolet añadiendo sin más la desinencia de pertenencia -anus/-ana.

\footnotetext{
97 Belasko, Diccionario etimológico de los nombres de los pueblos, villas y ciudades de Navarra, pp. 335-336.

98 Castro Toledo, Documentos de la Colegiata de Valladolid, 1084-1300.

99 Abajo Martín, Documentación de la catedral de Palencia (1035-1247).
} 
En tercer y cuarto lugar, los gentilicios vallisoletano/a y vallisoletense aparecen en la documentación en el último cuarto del siglo XII. Ambos surgieron a partir de Vallisolit, la latinización cultista de Valladolid, cuyo nombre fue erróneamente asimilado a un valle propiamente dicho; de ahí que también contengan la forma inicial vallis, al mismo tiempo que mantienen íntegramente el nombre Olit. Esta variante del gentilicio es la que ha pervivido hasta la actualidad, pasando del ámbito erudito al uso común con el tiempo, puesto que como bien señaló Hernández Alonso ${ }^{100}$ esto ha ocurrido en otros casos: Ciudad Rodrigo > mirobrigense (a partir del nombre de esta ciudad en época romana); Badajoz $>$ pacense (por su identificación errónea con la ciudad romana de Pax Iulia, que realmente corresponde a la portuguesa Beja); Lérida > ilerdense (junto con leridano/a, que es su forma procedente del romance); etc.

\section{El origen histórico de Valladolid}

Gracias al topónimo Valladolid podemos determinar cuándo se fundó este asentamiento y algunas de sus características primigenias y sus primeros habitantes; de ahí la importancia de haber desentrañado el origen del mismo. Al estar en lengua árabe nos aporta una cronología para la creación de este núcleo de población que se sitúa entre los siglos VIII y XI, periodo en el que esta lengua estuvo presente en el valle del Duero o, cuando menos, la población de esta zona mantenía apelativos y nombres de persona de origen árabe en el habla romance. Sin embargo, considero relevante comentar, aunque sea brevemente, la situación previa a este momento. Según aportan las evidencias arqueológicas, lo que hoy es el término municipal de Valladolid estuvo habitado desde época paleolítica hasta el tiempo de los pueblos celtas, más concretamente de los vacceos. Una vez producida la conquista romana de Hispania y la consecuente romanización del valle del Duero, se construyó una calzada romana de carácter secundario que pasaba por el actual casco histórico de Valladolid para conectar Septimanca (Simancas) con los territorios septentrionales de la cuenca del Duero discurriendo en paralelo al río Pisuerga. En la zona donde estuvo situada la iglesia de Santa María la Mayor de Valladolid, actualmente la plaza de la Universidad, hubo un pequeño emplazamiento de hábitat, que pudo ser un vicus, esto es, un grupo de casas de campesinos que trabajaban una pequeña explotación agrícola, o una villa, es decir, una casa de campo regida por un aristócrata latifundista que tenía al cargo a un campesinado, ya que se han descubierto algunos restos arqueológicos romanos. ${ }^{101}$ Además, en el término municipal vallisoletano, en el lado occidental del río Pisuerga, ha aparecido otra villa, conocida como Villa del Prado, cuyo basamento arquitectónico se ha conservado junto a un mosaico y unas termas. ${ }^{102}$ A lo largo de los siglos V y VI las villae romanas del valle del Duero entraron en deca-

\footnotetext{
100 Hernández Alonso, Nombre y renombre de Valladolid, p. 11.

101 Martín Montes y Moreda Blanco, "Aproximación a la génesis y desarrollo urbanístico de Valladolid durante la Plena Edad Media (siglos XI-XIII)", p. 163.

102 SÁnchez Simón, "El yacimiento "Villa romana de Prado"; Quintana López, "El estado actual del yacimiento de Villa de Prado".
} 
dencia hasta desaparecer. Algunas de ellas fueron reocupadas por el propio campesinado que trabajaba en ellas, ${ }^{103}$ pero no fue el caso para los dos asentamientos vallisoletanos descubiertos, ya que no hay signos de continuidad de uso en época visigoda. ${ }^{104} \mathrm{De}$ esta manera, quedaron abandonados y la población se reagrupó en otros asentamientos rurales existentes (castra, villae reconvertidas y aldeas) ${ }^{105}$ o muy probablemente hacia la ciudad fortificada más cercana, Septimanca (Simancas), puesto que era el elemento articulador y dinamizador del territorio en la desembocadura del Pisuerga y aledaños.

En algún momento indeterminado a partir del siglo VIII, siempre anterior a las primeras manifestaciones documentales sobre la existencia de Valladolid, que son de finales del siglo XI, el asentamiento fue reocupado. A tenor del nombre de Baldat Ulit este lugar fue una pequeña explotación agrícola que fue creciendo hasta ser más grande que una aldea, puesto que era una villa. Sabemos que las comunidades aldeanas, unidades básicas de gestión del territorio bajo el control jerárquico de un castellum o una ciudad fortificada, ${ }^{106}$ proliferaron en el valle del Duero durante este periodo debido a un crecimiento económico favorecido por un cambio climático que se produjo en el siglo X, pasando del Episodio Frío Altomedieval (c. 450-c. 950) al Periodo Cálido Medieval (c. 950-c. 1350). Estas comunidades aldeanas partían de una situación interna, en algunos casos, con una igualdad social en gran medida uniforme y, en otros casos, con un propietario que debido a su gran poder adquisitivo y militar dirigía al resto del campesinado; pero en poco tiempo todas se homogeneizaron, ya que en los primeros casos terminó sobresaliendo un campesino que fue obteniendo mayor beneficio económico por poseer más tierras, las cuales a su vez le permitieron tener mayor capacidad militar para atacar y defenderse de otras comunidades campesinas. ${ }^{107}$ Desconocemos de cuál de las dos

103 Chavarría Arnau, "Romanos y visigodos en el valle del Duero (siglos V-VIII)"; Chavarría Arnau, El final de las villae en Hispania (siglos IV-VII d.C.). Esta autora expone largo y tendido las razones históricas y las evidencias arqueológicas que demuestran estos hechos.

104 Palol y Wattenberg, Carta arqueológica de España, Valladolid, pp. 175-206. Hace un repaso pormenorizado a los yacimientos y restos arqueológicos encontrados hasta la fecha, que por desgracia apenas han aumentado.

105 Martín Viso, "Un mundo en transformación".

106 Martín Viso, "Una frontera casi invisible"; Martín Viso, "Espacios sin Estado". Concretamente este autor expone este modelo para el valle salmantino del Tormes y el valle portugués del Côa y propone su validez para los valles segovianos del Eresma y del Riaza.

${ }^{107}$ Sobre este asunto hay una interesante visión de conjunto que clarifica la realidad histórica de las autónomas comunidades humanas del valle del Duero que se fueron integrando en las estructuras sociales y políticas de León y Castilla en los siglos VIII-IX en Pérez Marinas, Tierra de nadie, pp. 178-184; pero también se pueden consultar individualmente los estudios en que esta obra se sustenta: Mínguez FernánDEZ, "Innovación y pervivencia en la colonización del valle del Duero", pp. 52-56; Mínguez Fernández, "La repoblación de los territorios salmantinos", pp. 21-27; Mínguez Fernández, "La frontera del Sistema Central”, pp. 212-215; Mínguez Fernández, La España de los siglos VI al XIII, pp. 139-140 y 255-260; Reyes Téllez, Población y sociedad, pp. 759-799 y 833-862; Moxó, Repoblación y sociedad en la España cristiana medieval, pp. 72-73; MARTín VISO, "Tumbas y sociedades locales en el centro de la Península Ibérica en la Alta Edad Media”, pp. 32-36; MARTín VISo, “¿Datar tumbas o datar procesos?”; MARTín Viso, "Paisajes sagrados, paisajes eclesiásticos", pp. 13-16; MARTín VISO, Poblamiento y estructuras sociales en el norte de la Peninsula Ibérica (siglos VI-XIII), pp. 165-166; WIскнам, Una historia nueva de la Alta Edad Media, pp. 335 y 812; Vieira, Alto Paiva, pp. 66-68; Blanco GonzÁlez, López-SÁez, Alba, Abel y 
situaciones partió la comunidad campesina de Valladolid, pero lo que parece plausible es la presencia en ella de un miembro destacado llamado Ulit.

Asimismo, tampoco podemos saber en qué momento sucedió tanto la fundación de Valladolid como la aparición de dicho Ulit, si antes o después de la integración del solar de Valladolid en los dominios del Reino de León, hecho que tuvo que suceder con la incorporación de la cercana Simancas a este espacio político. Esto ocurrió en el año 937 según la Crónica de Sampiro, ${ }^{108}$ si bien el Testamento de Cixila se redactó en el 927 en esta localidad ${ }^{109}$ y Alfonso IV se volvió a proclamar rey en el 932 en ella. ${ }^{110}$ A partir de entonces se produjo la repoblación de las tierras centrales de la ribera septentrional del Duero, que consistió, por un lado, en la reorganización administrativa mediante la absorción de los cuadros dirigentes de los núcleos de población preexistentes bajo el sistema feudal y, por otro lado, en la fundación de nuevos asentamientos humanos bajo también la estructura social, económica, política y jurisdiccional del feudalismo. ${ }^{111}$ Así pues, podría darse el caso de que Ulit fuera el antepasado de uno de los líderes de Valladolid del momento de la integración administrativa o la situación de que Ulit fuera el repoblador que fundó precisamente Valladolid (¿el presbítero Holit que aparece en el Testamento de Cixila?), siempre y cuando esta ya existiera desde la primera mitad del siglo $X$.

Con la dominación de estas tierras el solar de Valladolid quedó políticamente en la zona de frontera entre el Condado de Saldaña de los Banu Gómez, que controlaban Simancas, y el Condado de Monzón de los Banu Ansúrez, que poseían Cabezón de Pisuerga, hasta que ambos linajes se fundieron en uno a mediados del siglo XI. Bajo la protección de Simancas en el 939, Valladolid pudo evitar la depredación de las tropas andalusíes acaudilladas por el califa 'Abd al-Raḥmān III, ya que ante sus murallas ca-

Pérez, "Medieval landscapes in the Spanish Central System (450-1350)", pp. 8-9; PAStor Díaz de Garayo, Castilla en el tránsito de la Antigüedad al feudalismo, pp. 68-69, 90-92 y 97-98. También están presentes las obras de Martín Viso citadas en las dos notas previas. Aunque no atañen a la cuenca del Duero, sino al Alto Ebro, son también merecedores de consulta los estudios de David Peterson, que van en la misma línea de interpretación de la realidad histórica para esa otra región de dominio castellano.

108 SAmpiro, Sampiro, p. 305.

109 SÁez SÁnchez, Colección documental del Archivo de la Catedral de León (775-1230), vol. 1, doc. 75.

110 Ruiz Asencio, "La provincia de Valladolid en la Alta Edad Media (siglos VIII-XI)", pp. 11-12.

${ }^{111}$ De igual manera que se indica en una nota anterior, considero que hay una adecuada visión de conjunto sobre este asunto en Pérez Marinas, Tierra de nadie, pp. 184-191; pero indico de forma pormenorizada las obras en que este estudio se basa: Estepa Díez, Estructura social de la ciudad de León (siglos XI-XIII), pp. 66-73; Mínguez Fernández, "La despoblación del Duero", pp. 77-80; Mínguez Fernández, "La frontera del Sistema Central”, pp. 205-209; Mínguez Fernández, La España de los siglos VI al XIII, pp. 140-142; Barrios García, "Conquista y repoblación", pp. 231-233; Carvajal y Martín Viso, "Historias regionales de la repoblación", p. 41; MARTín Viso, Poblamiento y estructuras sociales en el norte de la Península Ibérica (siglos VI-XIII), pp. 240-241; Ruiz AsEncio, "La provincia de Valladolid en la Alta Edad Media (siglos VIII-XI)", pp. 14-15; Escalona Monge, "Comunidades, territorios y poder condal en la Castilla del Duero en el siglo X"; Álvarez Borge, Poder y relaciones sociales en Castilla en la Edad Media, pp. 83-85 y 112; Villar Garcí, La Extremadura castellano-leonesa, pp. 23, 61-62 y 70-71; Reglero DE LA Fuente, Espacio y poder en la Castilla medieval, p. 75; Pastor Díaz de Garayo, Castilla en el tránsito de la Antigüedad al feudalismo, p. 165. 
yeron la mayoría de ellas según nos narra Ibn Hayyān (987-1075) en su Al-Muqtabis. ${ }^{112}$ Sin embargo, no debió de contar con la misma suerte en el año 983 cuando la ciudad de Simancas fue tomada por los soldados del hââyib Al-Mansūr, hecho relatado por Al-'Udrī (1003-1085). ${ }^{113}$ Desde el ámbito de la jurisdicción eclesiástica Valladolid, si ya existía, perteneció a la Diócesis de León hasta una fecha indeterminada posterior al 952, luego al efímero obispado de Simancas hasta el $974,{ }^{114}$ de nuevo a la sede leonesa hasta el 1059 y finalmente, con la dotación concedida por el rey Fernando I de León, a la Diócesis de Palencia, ${ }^{115}$ donde permanecerá hasta la creación del obispado de Valladolid en el año 1595.

Una vez alejada la frontera con el territorio musulmán tras las conquistas de las ciudades del sur del Duero en la década de los años 70 del siglo XI y finalmente la toma de Toledo en el año 1085, el asentamiento vallisoletano empezó a florecer. Esta tarea recayó en Pedro Ansúrez, conde de Saldaña y Monzón, que fue nombrado señor de Valladolid por el rey Alfonso VI de León en 1072 o 1074 y también obtuvo a principios del siglo XII el señorío de las cercanas Simancas y Cabezón de Pisuerga, ${ }^{116}$ en cuyo alfoz se encontraba Valladolid según un documento de 1094. ${ }^{117}$ Gracias precisamente a la documentación más antigua conservada conocemos la fisionomía de Valladolid de esta época. Rodeada por una cerca y quizás con una torre de planta cuadrada como fortificación en la ubicación actual de la iglesia de San Benito el Real, estaba formada por dos barrios divididos por la calzada que atravesaba la villa. El occidental era el más antiguo, tenía como centro la iglesia de San Julián, destruida en 1777 y ubicada en la calle de la Encarnación, y contenía también la iglesia de San Pelayo, que ocupaba el espacio de la actual plaza de San Miguel y fue destruida igualmente en $1777 .{ }^{118} \mathrm{~A}$ colación de la advocación de estas iglesias se ha especulado sobre la procedencia de los antepasados de la población vallisoletana, en concreto si una parte sería leonesa y la otra andalusí (mozárabe); ${ }^{119}$ pero no me parece determinante por lo siguiente: a san

\footnotetext{
112 IBN Ḥayyān, Crónica del califa Abderramán III an-Násir entre los años 912 y 942 (Al-Muqtabis V), pp. 323-332.

113 AL-'UdRI, Fragmentos geográfico-históricos de Al-masālik ilà gamī al-mamalīk, p. 78. Este suceso es comentado en Ruiz Asencio, "La provincia de Valladolid en la Alta Edad Media (siglos VIII-XI)", pp. 40-42.

114 SÁnchez-Albornoz, El obispado de Simancas; Ruiz Asencio, "La provincia de Valladolid en la Alta Edad Media (siglos VIII-XI)", pp. 33-36.

115 VACa Lorenzo, "El obispado de Palencia desde sus orígenes hasta su definitiva restauración en el siglo XI", pp. 66-69.

116 Ruiz Asencio, "La provincia de Valladolid en la Alta Edad Media (siglos VIII-XI)", p. 52. Brevemente, en 1088, fue también señor de Cabezón.

117 Abajo Martín, Documentación de la catedral de Palencia (1035-1247), doc. 16, pp. 43-47.

118 Represa Rodríguez, "Origen y desarrollo urbano del Valladolid medieval (siglos X-XIII)”, pp. 65-79; Martín Montes y Moreda Blanco, "Aproximación a la génesis y desarrollo urbanístico de Valladolid durante la Plena Edad Media (siglos XI-XIII)", pp. 165-176.

119 Represa Rodríguez, "Origen y desarrollo urbano del Valladolid medieval (siglos X-XIII)”, p. 67. En concreto este autor considera que la iglesia de San Pelayo fue fundada por mozárabes en la segunda mitad del siglo X. Por mi parte utilizo el término mozárabe en el sentido de persona de cultura latina que vive en un territorio de dominio árabe, como es Al-Andalus, debido a que su uso está muy extendido en la
} 
Julián mártir, habitualmente junto a su esposa santa Basilisa, se le rendía culto en el Reino de León desde que el rey Alfonso II edificara una iglesia en su honor en Oviedo a principios del siglo IX, mientras que el culto de san Pelayo estaba extendido de igual manera por el Reino de León, ya que precisamente Pelayo fue un sobrino del obispo de Tuy apresado por el califa 'Abd al-Raḥmān III en la batalla de Valdejunquera (920) y ejecutado por él en Córdoba tras cinco años de cautiverio.

El barrio oriental fue desarrollado por el conde Pedro Ansúrez y todo él, junto con la iglesia de San Pelayo, fue donado a la iglesia de Santa María la Mayor. Esta fue fundada en la década de los años 80 del siglo XI por parte del conde Pedro Ansúrez y su esposa la condesa Eylo Alfónsez y fue erigida en estilo románico como centro de este nuevo barrio en la actual plaza de la Universidad, conservándose hoy en día solo una torre. Al mando de ella se puso al abad benedictino Salto, quien a finales del siglo XI obtuvo heredades para su iglesia a partir de ventas del matrimonio Fernando Hermenegíldiz y Juliana y los hermanos Diego y Fernando Véilaz, propietarios particulares, y sobre todo más donaciones realizadas por el propio Pedro Ansúrez y Martín Fláinez, señor de Simancas y Cabezón de Pisuerga. ${ }^{120}$ Este barrio dará la dinamización social y económica a Valladolid con la llegada de mercaderes y artesanos que se instalaron en su arteria principal, la calle de los Francos.

Asimismo, muy cerca de Valladolid, en el interior de un recodo del río Pisuerga al norte de la ciudad, donde se localiza actualmente una fábrica de neumáticos, ya existía el monasterio de San Cosme y San Damián, que fue donado en 1114 por la reina Urraca de León a la iglesia de Santa María la Mayor con todas sus pertenencias y tierras, situadas igualmente en la margen derecha del río Pisuerga, ${ }^{121}$ y fue desmantelado durante la ocupación francesa en 1812. ${ }^{122}$ A este lugar se llegaba desde Valladolid cruzando un puente sobre el río, ${ }^{123}$ seguramente en la misma ubicación en la que está el actual Puente Mayor.

Desde inicios del siglo XII hasta la muerte de Pedro Ansúrez, acaecida en 1118 o 1119 , la villa se fue expandiendo hacia el este y sudeste teniendo como eje la mencionada calle de los Francos y al mismo tiempo creándose nuevas parroquias: San Martín, Santa María Magdalena y San Esteban. También se le atribuye al conde la construcción por

comunidad investigadora, y también entre nuestra sociedad, a pesar de que estrictamente en época medieval se aplicaba en Oriente Próximo a una persona que hubiera pasado por un proceso de aculturación árabe o que descendiera de una persona arabizada. De hecho, literalmente mozárabe (musta'rab, مستعرب) significa 'arabizado' en lengua árabe. Para más información sobre mozárabe y otras denominaciones medievales árabes para los cristianos, consúltese Christys, Christians in al-Andalus, 711-1000, p. 8; Hitchcock, Mozarabs in Medieval and Early Modern Spain, pp. IX-X; Aillet, "Introduction"; y Pérez Marinas, Sansón de Córdoba, pp. 17-21.

120 Mañueco Villalobos y Zurita Nieto, Documentos de la Iglesia Colegial de Santa María la Mayor (hoy Metropolitana) de Valladolid, docs. 2, 4-7, pp. 7-10, 17-54. Estas heredades son citadas y comentadas en Ruiz Asencio, "La provincia de Valladolid en la Alta Edad Media (siglos VIII-XI)", pp. 59-61.

121 Castro Toledo, Documentos de la Colegiata de Valladolid, 1084-1300, doc. 19, pp. 53-54.

122 Benito y Durán, Monasterio de San Cosme y San Damián de Monjes Basilios (Valladolid).

123 Castro Toledo, Documentos de la Colegiata de Valladolid, 1084-1300, doc. 19, pp. 53-54. 
esta zona de un palacio y una iglesia vinculada al mismo, la de Santa María la Antigua, pero sobre el primero no hay pruebas de su existencia y sobre la segunda se desconoce fehacientemente cuándo se levantó su edificación primigenia. En este mismo periodo se produjo la independencia jurisdiccional de Valladolid, que dejó de ser sufragánea de Cabezón para ser el centro de un territorio propio. ${ }^{124}$ Es evidente que, tras el señorío de Pedro Ansúrez, Valladolid dejó de ser una simple villa agrícola para ser algo más, aunque aún quedaba mucho para que llegara a ser una ciudad de relieve como alcanzó a ser a partir de la Baja Edad Media.

Por último, es importante señalar otro elemento que denota el nombre de Baldat Ulit y es el hecho de que esté en árabe. Hay que recalcar la distinción de dos conceptos, cultura árabe y religión musulmana, ya que no son lo mismo y en muchos casos no van ligados. La cultura árabe tuvo un gran apogeo en Al-Andalus a partir del siglo IX, en la llamada fase orientalizante, y se extendió más allá de sus fronteras, llegando en nuestro caso al valle del Duero, puesto que era la cultura predominante de la Península Ibérica entre los siglos VIII y XI. De esta manera, las poblaciones cristianas de la cuenca del Duero, tanto autóctonas como migrantes andalusíes (mozárabes), empleaban asiduamente el árabe en su lengua romance, sobre todo una buena parte de su vocabulario, que ha pervivido en nuestro idioma hasta hoy en día. Además de terminología cotidiana, utilizaban de forma romanceada nombres de persona árabes. Esto se observa manifiestamente en la documentación más abundante conservada de un territorio hispánico al poco tiempo de ser conquistado por un reino cristiano durante la Alta Edad Media, que es la del monasterio de Lorvâo, en el valle portugués del Mondego. En estos documentos de los siglos X y XI se ha analizado que el 33,5\% de las personas mencionadas poseían nombres árabes comunes, como 'Abd Allāh, 'Abd al-Mālik, Hasan, Mutarraf, Mūsā, Ayyūb, Ibrāhīm, 'Umar, Hišām, Muḥammad o también Walīd, nombre crucial para nuestro estudio, y que esta antroponimia está presente indistintamente en terratenientes, aristócratas laicos y miembros de la Iglesia. ${ }^{125}$ Asimismo, estos antropónimos árabes se pueden leer con facilidad en la documentación del valle del Duero de los siglos VIIIXIII. ${ }^{126}$ Concretamente en la zona más cercana a Valladolid ya mencionamos algunos topónimos árabes anteriormente, pero hay que destacar tres que presentan antropónimos árabes: Mas'ūd (San Cebrián de Mazote), Aḥmad (Villahamete, rebautizada en el siglo XIX como Villagómez la Nueva, su nombre actual) e Ibrāhīm (Villabrágima). ${ }^{127}$ Todo esto permite explicar y contextualizar que Valladolid tenga una palabra tan común

\footnotetext{
124 Represa Rodríguez, "Origen y desarrollo urbano del Valladolid medieval (siglos X-XIII)”, pp. 65-79; Martín Montes y Moreda Blanco, "Aproximación a la génesis y desarrollo urbanístico de Valladolid durante la Plena Edad Media (siglos XI-XIII)", pp. 165-176.

125 Aillet, "El monasterio de Lorvâo y los confines de la Beira (siglos IX-XII)", pp. 71-95; Aillet, Les mozarabes, pp. 263-273 y 290-291.

126 Aguilar Sebastián y Rodríguez Mediano, "Antroponimia de origen árabe en la documentación leonesa (siglos VIII-XI)".

${ }^{127}$ Ruiz Asencio, "La provincia de Valladolid en la Alta Edad Media (siglos VIII-XI)", p. 24. Este autor indica que el primero es bereber, pero se utiliza en todo el mundo árabe, especialmente en Próximo Oriente.
} 
como 'villa' en árabe, baldat, y un antropónimo árabe romanceado, Ulit. A causa de la conquista realizada por parte del Reino de León y el Condado de Castilla (luego Reino de Castilla) y sobre todo debido a la consolidación de su dominio, la cultura árabe fue desapareciendo, olvidándose así el significado de baldat y confundiéndose su evolución fonética con la palabra romance valle y abandonándose paulatinamente los nombres árabes entre las personas cristianas.

Sin embargo, la presencia musulmana en el valle del Duero en estos siglos tuvo que ser muy escasa. Los estudios arqueológicos en las zonas rurales de los valles de Côa, Paiva, Duratón y Riaza muestran que los asentamientos no tenían una mezquita, sino un centro de culto cristiano (iglesia parroquial, ermita o cenobio), y que los enterramientos, tanto tumbas antropomorfas excavadas en la roca como cistas, seguían el rito cristiano de colocar al difunto en posición de decúbito supino. ${ }^{128}$ Por ello se piensa que la población musulmana que quedó en el valle del Duero tras el repliegue bereber de mediados del siglo VIII se pudo mantener en las principales ciudades, que aún no han sido excavadas, y en algunas zonas rurales muy concretas, como las que concentran topónimos en lengua bereber. ${ }^{129}$ A pesar de la escasez de información hay constancia de musulmanes convertidos al cristianismo en el valle del Duero, como cierto Malik del siglo X. ${ }^{130}$ Debido a esto no es totalmente descartable que Ulit, el fundador o al menos el que dio nombre a Valladolid, fuese musulmán y más aún no lo es si se tiene presente lo siguiente: al menos desde mediados del siglo XII hubo población musulmana en este lugar, como se vislumbra en la mención de personas con antropónimos árabes en la documentación (para esta época ya no son atribuibles a cristianos en una cultura árabe dominante), y sobre todo desde el siglo XIII con la existencia de una calleja de los Moros, que conectaba la calle de los Francos con la plaza de San Martín, esto es, en la zona de ampliación urbana de Pedro Ansúrez. En torno a esta calleja se encontró la aljama mudéjar desde el siglo XIV hasta 1414, cuando se hizo efectiva la prohibición de que los musulmanes habitaran en el centro de la ciudad. En ese momento la aljama mudéjar pasó a ubicarse a la Morería, que tras la obligación de conversión al cristianismo de 1502 se renombró como barrio de Santa María. ${ }^{131}$ El basamento de la mezquita de la Morería ha sido descubierto en 2019 en la calle de Claudio Moyano.

\section{Conclusiones}

Con este estudio, ante las dos hipótesis consolidadas hasta el momento sobre la procedencia del topónimo Valladolid, Balad Walìd y Vallis Tolitum, he pretendido demostrar su inviabilidad y presentar una propuesta que pueda resolver los escollos en la evolución

\footnotetext{
128 Martín Viso, “Tumbas y sociedades locales"; Martín Viso, "Paisajes sagrados, paisajes eclesiásticos"; Vieira, Alto Paiva, pp. 66-68; Reyes Téllez, Población y sociedad, pp. 759-771.

129 Pérez Marinas, Tierra de nadie, pp. 195-197.

130 Casado Quintanilla, "Melic (+960), presbítero, agricultor y ganadero: datos y conjeturas".

131 RePresa RodríGUez, "Origen y desarrollo urbano del Valladolid medieval (siglos X-XIII)”, p. 70; GómeZ RENAU, "La aljama de Valladolid: nuevas aportaciones”, pp. 145-149.
} 
fonética del término que dichas hipótesis planteaban, Baldat Ulit (su forma árabe no romanceada: بلدة وليد), cuyo significado es 'la villa de Walīd'. A partir de los testimonios más antiguos documentados de este topónimo hemos reconstruido el proceso lingüístico desde el origen propuesto hasta Valladolid, sin fallas, frente al resto de propuestas. Así, por un lado, Baldat /bældæt/, presente en la documentación más antigua oscilando entre Vala, Balad, Valad, Valat, Val de, Valde, Valded, Valed, Valid, Vallad, Vallas, Valle, Vallead, Valled, Valle de, Vallem, Valles, Vallis y Valt, se transforma en Vallad-/baKað/, debido al uso indistinto de la grafía B y V para el fonema inicial /b/, la simplificación de $/ \mathfrak{a} /$ en $/ \mathrm{a} /$, la conversión de $/ \mathrm{ld} /$ en $/ K /$ por la identificación del inicio de esta palabra con valle y la sonorización de /t/ en / $/$. Por otro lado, Ulit /ulit/, que aparece en las fuentes más antiguas del topónimo como oleti, oleto, oletum, olid, olide, olidi, olido, olio, olit, olite, olite, oliti, olith, olithi, olito y olliti, se convierte en -olid/olið/, a causa de la apertura de la / $\mathrm{u} /$ inicial en /o/ e, igualmente, la sonorización de la /t/ en / $/$ /, probablemente con un apoyo de una vocal /e/ paragógica, que facilitó este proceso y que después desapareció.

Pero no he recurrido solo a la filología, concretamente a las reglas de la evolución fonética en las lenguas iberorromances y a las características lingüísticas y morfológicas de la lengua árabe, sino también al análisis de las evidencias documentales que recogen sus formas más antiguas conservadas, teniendo siempre presente un contexto histórico (acontecimientos en el valle del Duero), material (restos arqueológicos) y cultural (arabización de poblaciones más allá de las fronteras de Al-Andalus) que lo hiciera posible.

Es este mismo contexto el que determina que, por las características del topónimo, Valladolid fue fundado entre los siglos VIII y XI como una comunidad campesina en la que destacó socialmente cierta persona llamada Walīd, en árabe, o Ulit, en romance siguiendo la tendencia onomástica de la época en la zona. Una posibilidad es que en los siglos VIII o IX comenzara a despuntar en ella por la acumulación de tierras de labor, lo que le permitió proveerse de mejor equipo militar ante rivalidades tanto cotidianas, contra otros asentamientos del entorno, como esporádicas, frente a contingentes de tropas enemigas de tierras lejanas (Reino de León, Al-Andalus), y así poder encabezar este pequeño grupo humano que se había instalado junto a una calzada romana entre Simancas y Cabezón para poner en cultivo campos regados a partir de las aguas de los ríos Pisuerga y Esgueva. Quizás en realidad, en los siglos X u XI, Walīd/Ulit fue un repoblador, un personaje preeminente de la zona al que se le encargó administrar una pequeña explotación agrícola que ya existía o que él mismo tuvo que fundar, bajo las órdenes del conde de Saldaña desde Simancas o del conde de Monzón desde Cabezón. Su nombre era árabe o romance de origen árabe, pero eso no supone necesariamente que Walīd/Ulit fuera un musulmán, ya que la cultura árabe y sobre todo su lengua, al igual que el romance con préstamos árabes, eran comunes en el valle del Duero, tanto entre la población autóctona como entre la procedente de Al-Andalus (mozárabes). Lo que es bien cierto es que la memoria de Walīd/Ulit no trascendió demasiado a la posterioridad, más allá de que se le considerase el fundador de Valladolid, aunque con el tiempo este honor ha quedado compartido con Pedro Ansúrez, gracias a que este conde 
puso en marcha un asentamiento agrícola de mediana entidad y logró que se convirtiera en una pequeña ciudad, con un centro religioso de cierta relevancia, la iglesia colegial de Santa María la Mayor, y con un barrio de comerciantes y artesanos que dinamizó la economía y atrajo nuevos habitantes.

\section{Anexos}

\section{Anexo I.}

\section{Topónimos de Valladolid en los documentos de los siglos XI y XII}

$\mathrm{ACP}=$ Archivo de la Catedral de Palencia ${ }^{132}$

$\mathrm{ACV}=$ Archivo de la Catedral de Valladolid ${ }^{133}$

AGS $=$ Archivo General de Simancas ${ }^{134}$

$\mathrm{DMC}=$ Documentos del monasterio de Santa María la Real de Aguilar de Campoo ${ }^{135}$

DME $=$ Documento del monasterio de San Román de Entrepeñas ${ }^{136}$

$\mathrm{DMO}=$ Documento del monasterio de Santa María de Villanueva de Oscos ${ }^{137}$

DMP $=$ Documentos del monasterio de San Pelayo de Oviedo ${ }^{138}$

$\mathrm{DMR}=$ Documentos del monasterio de Santa María de Retuerta ${ }^{139}$

DMS $=$ Documentos del monasterio de San Benito de Sahagún ${ }^{140}$

$\mathrm{DMV}=$ Documento del monasterio de Vega ${ }^{141}$

132 Abajo Martín, Documentación de la catedral de Palencia (1035-1247). Incluyo bajo esta signatura exclusivamente los documentos presentes en este libro que se conservan en el Archivo de la Catedral de Palencia. Por eso los que proceden del Archivo de la Catedral de Valladolid presentan la signatura de la edición correspondiente a este archivo.

133 Castro Toledo, Documentos de la Colegiata de Valladolid, 1084-1300. Incluyo bajo esta signatura exclusivamente los documentos presentes en este libro que se conservan en el Archivo de la Catedral de Valladolid. Por eso el que proviene del Archivo General de Simancas posee una signatura propia, los que proceden del Archivo de la Catedral de Palencia presentan la signatura de la edición correspondiente a este archivo y se ha optado por omitir tres documentos, dos del Archivo de la Catedral de Toledo (doc. 47, año 1154, Ualle Oleti, y doc. 60, año 1162, Vallis Oleti) y otro del Archivo de la Catedral de León (doc. 87, año 1198, Vallis Oleti), debido a que sus variantes del topónimo no aportan ninguna novedad. 134 Castro Toledo, Documentos de la Colegiata de Valladolid, 1084-1300, doc. 19. Se conserva en el Archivo General de Simancas, Consejo Real, 105-8, pieza II, ff. 63-64.

135 Rodríguez de Diego, Colección diplomática de Santa María de Aguilar de Campoo (852-1230).

136 AHN, San Román de Entrepeñas, no 16 bis. Copiado de Montenegro Duque, "El origen céltico del nombre de Valladolid y la difusión de la raíz "tol” en la toponimia y hablas hispanas", p. 37.

137 Floriano Llorente, “Colección diplomática del monasterio de Villanueva de Oscos. Primera serie: (años 1136-1200)", pp. 135-136.

138 Serrano, Cartulario de monasterio de Vega con documentos de San Pelayo y Vega de Oviedo.

139 Antón, "Monasterio de Retuerta. Documentos".

140 Fernández Flórez, Colección diplomática del monasterio de Sahagún (857-1300).

141 Serrano, Cartulario de monasterio de Vega con documentos de San Pelayo y Vega de Oviedo. 


\begin{tabular}{|c|c|c|c|c|}
\hline Fuente & Doc. & Año & Topónimo & Expresión \\
\hline $\mathrm{ACV}$ & 2 & 1088 & Ualaolit & ad Sancta Maria de Ualaolit \\
\hline $\mathrm{ACV}$ & 3 & 1089 & Ualleolid & $\begin{array}{l}\text { de hereditatibus Sancte Marie de } \\
\text { Ualleolid }\end{array}$ \\
\hline $\mathrm{ACV}$ & 4 & 1092 & Ualledolidi & ad Sanctam Mariam de Ualledolidi \\
\hline $\mathrm{ACV}$ & 4 & 1092 & Uallisoliti & ad ereditatem Sancte Marie Uallisoliti \\
\hline $\mathrm{ACV}$ & 4 & 1092 & Ualleolide & Sancte Marie de Ualleolide \\
\hline $\mathrm{ACV}$ & 5 & 1093 & Ualatoliti & ad Sancta Maria de Ualatoliti \\
\hline $\mathrm{ACP}$ & $16^{142}$ & 1094 & Ualleoliti & $\begin{array}{l}\text { omniumque parentum nostrorum, eclesie } \\
\text { Sancte Marie de Ualleoliti }\end{array}$ \\
\hline $\mathrm{ACP}$ & 16 & 1094 & Ualleoliti & in Ualleoliti \\
\hline $\mathrm{ACP}$ & 16 & 1094 & Ualleoliti & de Ualleoliti \\
\hline $\mathrm{ACP}$ & 16 & 1094 & Ualleoliti & in Ualleoliti \\
\hline $\mathrm{ACP}$ & 16 & 1094 & Ualleoliti & in Ualleoliti \\
\hline $\mathrm{ACV}$ & $7^{143}$ & 1095 & Uallisoliti & $\begin{array}{l}\text { mediatatem Ecclesie beatȩ Marie Ualli } \\
\text { soliti }\end{array}$ \\
\hline $\mathrm{ACV}$ & 8 & 1095 & Ualleolit & Ecclesie Sancte Marie de Ualleolit \\
\hline $\mathrm{ACV}$ & 8 & 1095 & Ualleolit & ipsas de Ualleolit \\
\hline $\mathrm{ACV}$ & 9 & 1095 & Ualleoliti & $\begin{array}{l}\text { omniumque parentum nostrorum, ȩclesię } \\
\text { Sanctę Marię de Ualleoliti }\end{array}$ \\
\hline $\mathrm{ACV}$ & 9 & 1095 & Uallisoliti & Sanctę Marię Uallisoliti \\
\hline $\mathrm{ACV}$ & 9 & 1095 & Ualadolid & De Ualadolid \\
\hline $\mathrm{ACV}$ & 10 & 1100 & Ualladolit & Sanctę Marię de Ualladolit \\
\hline $\mathrm{ACV}$ & 10 & 1100 & Ualladolit & de Sancta Maria de Ualladolit \\
\hline $\mathrm{ACV}$ & 10 & 1100 & Ualladolit & de Sancta Maria de Ualladolit \\
\hline $\mathrm{ACV}$ & 10 & 1100 & Ualladolit & in Ualladolit \\
\hline $\mathrm{ACP}$ & 20 & 1103 & Ualladolite & in uilla quam diccunt Ualladolite \\
\hline $\mathrm{ACP}$ & 20 & 1103 & Ualladolite & in uilla quam diccunt Ualladolite \\
\hline $\mathrm{ACV}$ & 13 & 1110 & Uallisolith & uilla quę uocatur Uallisolith \\
\hline $\mathrm{ACV}$ & 13 & 1110 & Uallisolith & bonorum hominum Uallisolith \\
\hline $\mathrm{ACV}$ & 14 & 1110 & Valladolit & ecclesie Sancte Marie de Valladolit \\
\hline
\end{tabular}




\begin{tabular}{|c|c|c|c|c|}
\hline $\mathrm{ACV}$ & 14 & 1110 & Valleoleti & medietatem abbati Valleoleti \\
\hline $\mathrm{ACV}$ & 14 & 1110 & Ualadolit & ad Sancta Maria de Ualadolit \\
\hline $\mathrm{ACV}$ & 15 & 1110 & Ualadolidi & de Ualadolidi \\
\hline $\mathrm{ACV}$ & 17 & 1111 & Ualleoleti & ecclesie beate Marie Ualleoleti \\
\hline $\mathrm{ACV}$ & 17 & 1111 & Ualleoleti & in illa ecclesie Beate Marie Ualleoleti \\
\hline $\mathrm{ACV}$ & 17 & 1111 & Ualleoliti & in Ualleoliti \\
\hline $\mathrm{ACV}$ & 18 & 1112 & Ualladolidi & in territorio de Ualladolidi \\
\hline $\mathrm{ACV}$ & 18 & 1112 & Uallisoliti & concilio toto Uallisoliti \\
\hline AGS & & 1114 & Valleadolito & ecclesie Sancte Marie de Valleadolito \\
\hline AGS & & 1114 & Valleadolliti & ad caput pontis de Valleadolliti \\
\hline $\mathrm{ACV}$ & 20 & 1114 & Baladolid & in Baladolid \\
\hline $\mathrm{ACV}$ & 22 & 1115 & Ualladolidi & in uilla que uocitant Ualladolidi \\
\hline $\mathrm{ACV}$ & 22 & 1115 & Ualladolidi & Sancta Maria dico de Ualladolidi \\
\hline $\mathrm{ACV}$ & 22 & 1115 & Uallisoliti & domum Sancte Marie Uallisoliti \\
\hline $\mathrm{ACV}$ & 22 & 1115 & Ualladolidi & in Ualladolidi \\
\hline $\mathrm{ACV}$ & 23 & 1115 & Uallisoliti & uilla que uocitant Uallisoliti \\
\hline $\mathrm{ACV}$ & 23 & 1115 & Uallisoliti & Sancta Maria de Uallisoliti \\
\hline $\mathrm{ACV}$ & 23 & 1115 & Uallasoliti & ad omnium Sancte Marie Uallasoliti \\
\hline $\mathrm{ACV}$ & 23 & 1115 & Ualladolidi & De Ualladolidi \\
\hline $\mathrm{ACV}$ & 24 & 1115 & Ualadolid & in Ualadolid \\
\hline $\mathrm{ACV}$ & 25 & 1115 & Ualle Oliti & uilla que uocitant Ualle Oliti \\
\hline $\mathrm{ACV}$ & 25 & 1115 & Ualladolide & Sancta Maria dico de Ualladolide \\
\hline $\mathrm{ACV}$ & 25 & 1115 & Ualladolide & De Ualladolide \\
\hline $\mathrm{ACV}$ & 26 & 1115 & Uallisolite & Uilla que uocitant Uallisolite \\
\hline $\mathrm{ACV}$ & 26 & 1115 & Ualladolitę & sancta Maria dico de Ualladolitę \\
\hline $\mathrm{ACV}$ & 26 & 1115 & Uallisolitȩ & ęclesię Sanctę Marię Uallisolitę \\
\hline $\mathrm{ACV}$ & 26 & 1115 & Valladolide & De Valladolide \\
\hline $\mathrm{ACP}$ & 25 & 1116 & Ualladolit & Sancta Maria de Ualladolit \\
\hline $\mathrm{ACP}$ & 25 & 1116 & Valladolit & Valladolit \\
\hline $\mathrm{ACV}$ & 27 & 1117 & Ualladolidi & in uilla que uocitant Ualladolidi \\
\hline $\mathrm{ACV}$ & 27 & 1117 & Uallisoliti & Totum concilio de Uallisoliti \\
\hline $\mathrm{ACV}$ & 28 & 1117 & Ualle Olit & ad domum Sancte Marie de Ualle Olit \\
\hline $\mathrm{ACP}$ & 27 & 1117 & Ualleadolite & Ecclesiam Sancte Marie de Ualleadolite \\
\hline $\mathrm{ACP}$ & 30 & 1125 & Ualledolit & Sancta Maria de Ualledolit \\
\hline $\mathrm{ACP}$ & 30 & 1125 & Valledolit & Valledolit \\
\hline
\end{tabular}




\begin{tabular}{|c|c|c|c|c|}
\hline $\mathrm{ACV}$ & 36 & 1135 & Valleoleti & Sancte Marie Valleoleti \\
\hline $\mathrm{ACV}$ & 36 & 1135 & Valleoleti & predicte ecclesie Sancte Marie Valleoleti \\
\hline DMO & 2 & 1137 & Ualaolith & in Ualaolith \\
\hline $\mathrm{ACP}$ & 35 & 1140 & Valedolith & Sanctam Mariam de Valedolith \\
\hline DMV & 42 & 1141 & Valladolid & in Valladolid \\
\hline DMV & 42 & 1141 & Valladolide & toto concilio de Valladolide \\
\hline $\mathrm{ACP}$ & 37 & 1142 & Ualedolio & Ualedolio \\
\hline DMS & 1278 & 1143 & Valledolit & Ego Cit Memez de Valledolit \\
\hline $\mathrm{ACP}$ & 38 & 1143 & Ualedolido & $\begin{array}{l}\text { fidelibus suis et amicis omnibus } \\
\text { hominibus de Ualedolido }\end{array}$ \\
\hline $\mathrm{ACP}$ & 39 & 1143 & Ualledolit & ecclesiam Sancte Marie de Ualledolit \\
\hline $\mathrm{ACP}$ & 41 & 1143 & Ualledolit & Ualledolit \\
\hline $\mathrm{ACP}$ & 41 & 1143 & Ualladolith & ecclesiam Sancte Marie de Ualladolith \\
\hline DMP & 9 & 1145 & Vallem Oletum & apud Vallem Oletum \\
\hline DMP & 10 & 1145 & Vallem Oletum & apud Vallem Oletum \\
\hline DMR & $1^{\mathrm{a}}, 5$ & 1148 & Valladolite & in Valladolite \\
\hline DMR & $1^{\mathrm{a}}, 5$ & 1148 & Valladolit & in Valladolit \\
\hline DMR & $1^{\mathrm{a}}, 5$ & 1148 & Valladolit & De bonis hominibus de Valladolit \\
\hline DMR & $1^{\mathrm{a}}, 5$ & 1148 & Valladolit & toto conceio de Valladolit \\
\hline DMS & $1299 \mathrm{~A}$ & A1148 & Ualle Oliti & in Ualle Oliti \\
\hline DMS & 1299B & 31148 & Ual de Oliti & in Ual de Oliti \\
\hline DMS & 1300 & 1148 & Ualle Oliti & in Ualle Oliti \\
\hline $\mathrm{ACV}$ & 44 & 1151 & Ualleoliti & in Ualleoliti \\
\hline $\mathrm{ACV}$ & 44 & 1151 & Uallis Oliti & Sanctę Marię Uallis Oliti \\
\hline DMS & 1312 & 1152 & Ualle de Olid & in Ualle de Olid \\
\hline $\mathrm{ACV}$ & 45 & 1152 & Uallis Oliti & in villa quę dicitur Uallis Oliti \\
\hline $\mathrm{ACV}$ & 46 & 1152 & Uallisolith & ecclesie Sancte Marie Uallisolith \\
\hline $\mathrm{ACV}$ & 46 & 1152 & Uallisolith & ecclesie Sancte Marie Uallisolith \\
\hline $\mathrm{ACV}$ & 46 & 1152 & Uallisolith & in Uallisolith \\
\hline DME & & 1153 & Validolit & \\
\hline DMR & $1^{\mathrm{a}}, 10$ & 1154 & Valledolito & in Valledolito \\
\hline $\mathrm{ACP}$ & 51 & 1155 & Ualleoletum & apud Ualleoletum \\
\hline $\mathrm{ACP}$ & 51 & 1155 & Ualleoleto & a Ualleoleto \\
\hline $\mathrm{ACP}$ & 53 & 1155 & Valleoleti & vniverso capitulo Valleoleti \\
\hline DMS & 1320 & 1155 & Ualle Olit & in Ualle Olit \\
\hline
\end{tabular}




\begin{tabular}{|c|c|c|c|c|}
\hline ACV & 49 & 1155 & Ualleolith & concilio de Ualleolith \\
\hline $\mathrm{ACV}$ & 49 & 1155 & Ualleolithi & $\begin{array}{l}\text { Saluador Gonsaluez, tunc temporibus } \\
\text { imperatoris maiorinus Ualleolithi }\end{array}$ \\
\hline $\mathrm{ACP}$ & 54 & 1155 & Valleoleti & ecclesiam Valleoleti \\
\hline $\mathrm{ACP}$ & 55 & 1155 & Ualleoleti & uniuerso capitulo Ualleoleti \\
\hline ACV & 52 & 1155 & Uallisoleti & concilio Uallisoleti \\
\hline $\mathrm{ACV}$ & 54 & 1156 & Ualleoliti & ecclesie beate Marie Ualleoliti \\
\hline ACV & 54 & 1156 & Ualle Oliti & in Ualle Oliti \\
\hline $\mathrm{ACV}$ & 55 & 1158 & Uallisolithi & ęcclesię Sanctę Marię Uallisolithi \\
\hline $\mathrm{ACV}$ & 55 & 1158 & Uallisolithi & prefate ecclesiae beate Marie Uallisolithi \\
\hline ACV & 56 & 1158 & Ualleoliti & illas casas de Ualleoliti \\
\hline $\mathrm{ACV}$ & 56 & 1158 & Ualleoliti & in Ualleoliti \\
\hline ACV & 57 & 1159 & Uallis Oleti & abbati ecclesie Uallis Oleti \\
\hline $\mathrm{ACV}$ & 58 & 1159 & Uallisolithi & ęcclesię Sanctę Marię Uallisolithi \\
\hline $\mathrm{ACV}$ & 58 & 1159 & Ualadolid & ecclesia de Ualadolid \\
\hline ACV & 59 & 1160 & Uallisolith & ęcclesię Sanctę Marię Uallisolith \\
\hline $\mathrm{ACV}$ & 59 & 1160 & Uallisolith & $\begin{array}{l}\text { ecclesie Sanctę Marię Uallisolith prefatam } \\
\text { hereditatem }\end{array}$ \\
\hline ACV & 59 & 1160 & Uallisolith & ęcclesię Sanctę Marie Uallisolith \\
\hline $\mathrm{ACV}$ & 59 & 1160 & Uallisolith & in Uallisolith \\
\hline DCV & 59 & 1160 & Uallisoleti & in ęcclesia Uallisoleti \\
\hline $\mathrm{ACV}$ & 59 & 1160 & Uallisolith & concilium Uallisolith \\
\hline $\mathrm{ACP}$ & 62 & 1162 & Valledolit & Valledolit \\
\hline $\mathrm{ACP}$ & 62 & 1162 & Valladolith & $\begin{array}{l}\text { ecclesiam, quoque, Sancte Marie de } \\
\text { Valladolith }\end{array}$ \\
\hline DMR & $2^{\mathrm{a}}, 4$ & 1165 & Valleoliti & in Valleoliti \\
\hline $\mathrm{ACP}$ & 70 & 1166 & Ualdedolid & $\begin{array}{l}\text { eclesiam Beate Marie semper Uirginis } \\
\text { de Ualdedolid }\end{array}$ \\
\hline $\mathrm{ACP}$ & 70 & 1166 & Uallisoleti & super aeclesia Uallisoleti \\
\hline $\mathrm{ACP}$ & 71 & 1169 & Uallemoleti & aput Uallemoleti \\
\hline $\mathrm{ACV}$ & 63 & 1169 & Uallisoleti & uniuersis clericis Sante Marie Uallisoleti \\
\hline $\mathrm{ACV}$ & 63 & 1169 & Uallemoleti & aput Uallemoleti \\
\hline DMR & $2^{\mathrm{a}}, 7$ & 1170 & Valladolid & testes de Valladolid \\
\hline DMR & $2^{\mathrm{a}}, 8$ & 1170 & Valleolid & testes de Valleolid \\
\hline DMR & $2^{\mathrm{a}}, 9$ & 1170 & Valtolid & Martin Dominguez de Valtolid \\
\hline
\end{tabular}




\begin{tabular}{|c|c|c|c|c|}
\hline $\mathrm{ACV}$ & 64 & 1171 & Ualleoliti & Ego, Dominicus, abbas Ualleoliti \\
\hline $\mathrm{ACV}$ & 64 & 1171 & Ualleoliti & abbatibus Sancte Marie Ualleoliti \\
\hline $\mathrm{ACV}$ & 64 & 1171 & Ualleoliti & Sancte Marie Ualleoliti \\
\hline $\mathrm{ACV}$ & 64 & 1171 & Ualleoliti & Ego, Dominicus, abbas Ualleoliti \\
\hline $\mathrm{ACP}$ & 76 & 1175 & Ualleoleti & Ualleoleti \\
\hline $\mathrm{ACV}$ & 65 & 1175 & Uallisoleti & in Uallisoleti \\
\hline $\mathrm{ACV}$ & 65 & 1175 & Uallisoleti & Totum concilium Uallisoleti \\
\hline $\mathrm{ACV}$ & 66 & 1175 & Uallisoleti & tociusque capituli et concilii Uallisoleti \\
\hline $\mathrm{ACV}$ & 66 & 1175 & Uallisoleti & in Uallisoleti \\
\hline $\mathrm{ACV}$ & 66 & 1175 & Uallisoleti & Totum concilium Uallisoleti \\
\hline $\mathrm{ACV}$ & 67 & 1177 & Uallisoleti & uniuersis Uallisoleti clericis \\
\hline $\mathrm{ACV}$ & 68 & 1177 & Uallisoleti & Sancta Maria Uallisoleti \\
\hline $\mathrm{ACV}$ & 69 & 1177 & Ualleolithi & $\begin{array}{l}\text { abbatem Petrum, conseruatorem ęcclesię } \\
\text { Sanctę Marię Ualleolithi }\end{array}$ \\
\hline $\mathrm{ACV}$ & 70 & 1177 & Vallisoleti & in uilla Vallisoleti \\
\hline $\mathrm{ACV}$ & 70 & 1177 & Vallisoleti & ecclesie Sancte Marie Vallisoleti \\
\hline $\mathrm{ACV}$ & 71 & 1178 & Uallisoleti & ecclesie beate Marie Uallisoleti \\
\hline $\mathrm{ACV}$ & 71 & 1178 & Uallisoletum & apud Uallisoletum \\
\hline $\mathrm{ACV}$ & 72 & 1178 & Uallisoleti & $\begin{array}{l}\text { omnes hereditates, domos et ganatos } \\
\text { ecclesie Sancte Marie Uallisoleti }\end{array}$ \\
\hline $\mathrm{ACV}$ & 72 & 1178 & Uallisoleti & Uallisoleti \\
\hline $\mathrm{ACP}$ & 86 & 1179 & Uallisoletum & apud Uallisoletum \\
\hline $\mathrm{ACV}$ & 73 & 1181 & Uallisoliti & Petri, abbatis Uallisoliti \\
\hline $\mathrm{ACV}$ & 73 & 1181 & Ualleoleti & $\begin{array}{l}\text { omnes domos, hereditates, collacios et } \\
\text { ganados ęcclesię Sancte Marie Ualleolet }\end{array}$ \\
\hline $\mathrm{ACV}$ & 74 & 1181 & Ualleoliti & ego, P[etrus], Dei gratia Ualleoliti abbas \\
\hline $\mathrm{ACV}$ & 74 & 1181 & Ualleoliti & Ego, abbas P[etrus] ecclesie Ualleoliti \\
\hline $\mathrm{ACV}$ & 75 & 1182 & Uallemoleti & Fernandus Aries, senior in Uallemoleti \\
\hline $\mathrm{ACP}$ & 93 & 1182 & Valladolit & Valladolit \\
\hline $\mathrm{ACP}$ & 93 & 1182 & Ualladolit & $\begin{array}{l}\text { ecclesiam, quoque, Sancte Marie de } \\
\text { Ualladolit }\end{array}$ \\
\hline $\mathrm{DMC}$ & 50 & 1182 & Vallisoleti & ab acenariis Vallisoleti \\
\hline $\mathrm{ACV}$ & 77 & 1182 & Uallis Oleti & Petro, abbate Sancte Marie Uallis Oleti \\
\hline $\mathrm{ACV}$ & 79 & 1184 & Uallisoleti & $\begin{array}{l}\text { utilitati et honori ecclesie beate Marie } \\
\text { Uallisoleti }\end{array}$ \\
\hline
\end{tabular}




\begin{tabular}{|c|c|c|c|c|}
\hline $\mathrm{ACV}$ & 80 & 1187 & Uallisoleti & ecclesie beate Marie Uallisoleti \\
\hline $\mathrm{ACV}$ & 81 & 1188 & Uallisoletum & Guterrio Roderici Uallisoletum dominante \\
\hline DMS & 1443 & 1188 & Ualdeolit & in Ualdeolit \\
\hline DMS & 1443 & 1188 & Ualdeolit & $\begin{array}{l}\text { quatuor senibus et probis hominibus de } \\
\text { Ualdeolit }\end{array}$ \\
\hline $\mathrm{ACV}$ & 82 & 1190 & Uallisoleti & $\begin{array}{l}\text { dompno Petro Secundo, ecclesie Sancte } \\
\text { Marie Uallisoleti abbati }\end{array}$ \\
\hline $\mathrm{ACV}$ & 82 & 1190 & Uallisoleti & $\begin{array}{l}\text { Comite Fernando Poncii, Uallisoleti } \\
\text { dominante }\end{array}$ \\
\hline $\mathrm{ACP}$ & 109 & 1191 & Vallisoletum & apud Vallisoletum \\
\hline DMC & 76 & 1192 & Ualisoletum & prope Ualisoletum \\
\hline DMS & 1497 & 1195 & Ualleoleti & in Ualleoleti \\
\hline $\mathrm{ACV}$ & 85 & 1195 & Uallemoleti & apud Uallemoleti \\
\hline $\mathrm{ACV}$ & 86 & 1197 & Ualleoleti & $\begin{array}{l}\text { ego, Petrus Secundus, abbas ecclesie } \\
\text { Ualleoleti }\end{array}$ \\
\hline $\mathrm{ACV}$ & 86 & 1197 & Ualleoleti & ad opus ecclesie Sancte Marie Ualleoleti \\
\hline $\mathrm{ACV}$ & 86 & 1197 & Uallemoleti & apud Uallemoleti \\
\hline $\mathrm{ACV}$ & 86 & 1197 & Ualleoleti & $\begin{array}{l}\text { Nos itaque, Petrus Secundus, abbas } \\
\text { ecclesie Ualleoleti }\end{array}$ \\
\hline $\mathrm{ACV}$ & 88 & 1200 & Ualleoleti & ecclesiam Ualleoleti \\
\hline $\mathrm{ACV}$ & 88 & 1200 & Ualleoleti & Petrum, abbatem Ualleoleti \\
\hline $\mathrm{ACV}$ & 88 & 1200 & Ualleoleti & ecclesia Ualleoleti \\
\hline $\mathrm{ACV}$ & 88 & 1200 & Ualleoleti & homines Ualleoleti \\
\hline $\mathrm{ACV}$ & 88 & 1200 & Ualleoleti & ecclesia Ualleoleti \\
\hline $\mathrm{ACV}$ & 88 & 1200 & Ualleoleti & ecclesie Ualleoleti \\
\hline $\mathrm{ACV}$ & 88 & 1200 & Ualleoleti & ecclesie Ualleoleti \\
\hline $\mathrm{ACV}$ & 88 & 1200 & Ualleoleti & homines Ualleoleti \\
\hline $\mathrm{ACV}$ & 88 & 1200 & Ualleoleti & in ecclesiis Ualleoleti \\
\hline $\mathrm{ACV}$ & 88 & 1200 & Ualleoleti & concilium Ualleoleti \\
\hline $\mathrm{ACV}$ & 88 & 1200 & Ualleoleti & abbas Ualleoleti \\
\hline $\mathrm{ACV}$ & 88 & 1200 & Ualleoleto & in Ualleoleto \\
\hline $\mathrm{ACV}$ & 88 & 1200 & Ualleoletum & apud Ualleoletum \\
\hline $\mathrm{ACV}$ & 88 & 1200 & Ualleoleti & Ego, Petrus, abbas Ualleoleti \\
\hline
\end{tabular}




\begin{abstract}
Anexo II.
ACP $=$ Archivo de la Catedral de Palencia ${ }^{144}$

$\mathrm{ACV}=$ Archivo de la Catedral de Valladolid ${ }^{145}$
\end{abstract}

Gentilicios de Valladolid en los documentos de los siglos XI y XII

\begin{tabular}{|c|c|c|c|c|}
\hline Fuente & Doc. & Año & Gentilicio & Expresión \\
\hline $\mathrm{ACP}$ & 22 & 1110 & baladolensi & $\begin{array}{l}\text { domino Deo atque eius Marie Matri } \\
\text { Semper genitrici Uirgini, baladolensis } \\
\text { sedis }\end{array}$ \\
\hline $\mathrm{ACP}$ & 22 & 1110 & baladolensi & $\begin{array}{l}\text { monasterio Sancte Marie baladolensi } \\
\text { sedis }\end{array}$ \\
\hline $\mathrm{ACV}$ & 20 & 1114 & baladonensi & Sanctę Marię baladonensi \\
\hline $\mathrm{ACV}$ & 21 & 1114 & baladolensi & $\begin{array}{l}\text { eius Genitricis Semper Uirginis Marie } \\
\text { baladolensi }\end{array}$ \\
\hline $\mathrm{ACV}$ & 21 & 1114 & baladonensi & Sanctę Marię baladonensi \\
\hline $\mathrm{ACV}$ & 21 & 1114 & baladolensi & Sanctę Marię baladolensi \\
\hline $\mathrm{ACV}$ & 24 & 1115 & ualadolensi & Sanctę Marię ualadolensi \\
\hline $\mathrm{ACV}$ & 24 & 1115 & ualadolensi & Sanctę Marię ualadolensi \\
\hline $\mathrm{ACV}$ & 65 & 1175 & uallisolitane & $\begin{array}{l}\text { ego, Pe[trus], uallisolitane ecclesie gratia } \\
\text { Dei Abbas }\end{array}$ \\
\hline $\mathrm{ACV}$ & 66 & 1175 & uallisolitane & ego, Petrus, uallisolitane ecclesie Abbas \\
\hline $\mathrm{ACV}$ & 75 & 1182 & ualleoletane & $\begin{array}{l}\text { ego, } \mathrm{P}[\text { etrus], Dei nutu ualleoletane } \\
\text { ecclesie dictus abbas }\end{array}$ \\
\hline $\mathrm{ACV}$ & 81 & 1188 & uallisoletane & $\begin{array}{l}\text { ego, } \mathrm{P}[\text { etrus }] \text {, Dei gratia uallisoletane } \\
\text { ecclesie dictus abbas }\end{array}$ \\
\hline $\mathrm{ACV}$ & 81 & 1188 & uallisoletane & $\begin{array}{l}\mathrm{P}[\text { etro] de Cruce, uallisoletane ecclesie } \\
\text { abbate existente }\end{array}$ \\
\hline $\mathrm{ACV}$ & 83 & 1190 & uallisoletensi & $\begin{array}{l}\text { uallisoletensi ecclesie beate Uirginis } \\
\text { Marie }\end{array}$ \\
\hline $\mathrm{ACV}$ & 84 & 1190 & uallisoletensi & ecclesie uallisoletensi \\
\hline $\mathrm{ACV}$ & 85 & 1195 & ualleoletane & abbas Petrus ualleoletane eclesie \\
\hline $\mathrm{ACV}$ & 88 & 1200 & ualleoletanis & De ualleoletanis \\
\hline
\end{tabular}

\footnotetext{
144 Abajo Martín, Documentación de la catedral de Palencia (1035-1247).

145 Castro Toledo, Documentos de la Colegiata de Valladolid, 1084-1300.
} 


\section{Bibliografía citada}

\section{Diccionarios}

Corriente, Federico, Ferrando, Ignacio, y Ould Mohamed Baba, Ahmed Salem, Diccionario avanzado árabe, Herder, Barcelona, 2005-2010, 2 vols.

Segura Munguía, Santiago, Nuevo diccionario etimológico latín-español y de las voces derivadas, Universidad de Deusto, Bilbao, 2010.

\section{Fuentes}

Abajo Martín, Teresa, Documentación de la catedral de Palencia (1035-1247), Ediciones J. Garrido Garrido, Burgos, 1986.

Alonso de Torres, García, Espejo de la nobleza, Biblioteca Nacional de España, MSS/11423.

Antolínez de Burgos, Juan, Historia de Valladolid, Imprenta y Librería Nacional y Extranjera de Hijos de Rodríguez, Valladolid, 1887.

AnTón, Francisco, "Monasterio de Retuerta. Documentos", Revista histórica. Órgano de la Facultad de Historia de Valladolid, $2^{\mathrm{a}}$ época, 4 (1924), pp. 172-182, 5 (1925), pp. 25-32, 6 (1925), pp. 60-65, 8 (1925), pp. 199-204, 9 (1926), pp. 11-16, 10 (1926), pp. 59-60, 11 (1926), pp. 110-114.

Arredondo, Gonzalo de, Historia del conde Fernán González, Biblioteca Nacional de España, MSS/2788.

Castillo, Julián del, Historia de los reyes godos que vinieron de la Scitia de Europa contra el Imperio romano y a España, y la successión dellos hasta el cathólico y potentíssimo don Philippe segundo rey de España, a quien va dirigida, Felipe de Junta, Burgos, 1582.

Una crónica anónima de Abd al-Rahman III al-Nasir, Évariste Lévi-Provençal y Emilio García Gómez (eds.), Instituto Miguel Asín, Madrid-Granada, 1950, pp. 123-124.

Castro Toledo, Jonás, Documentos de la Colegiata de Valladolid, 1084-1300, DipuTACIÓN de Valladolid, Valladolid, 2010.

Fernández Flórez, José Antonio, Colección diplomática del monasterio de SAhagún (857-1300), Centro de Estudios e Investigación "San Isidoro" (CSIC-CECEL), León, 1991, vol. 4.

Floriano Llorente, Pedro, "Colección diplomática del monasterio de Villanueva de Oscos. Primera serie: (años 1136-1200)”, Boletín del Instituto de Estudios Asturianos, 102 (1981), pp. 127-190.

El Fuero de Madrid, Javier Alvarado Planas y Gonzalo Oliva Manso (eds.), Agencia Estatal Boletín Oficial del Estado, Madrid, 2019. 
Gil Fernández, Juan, Crónicas asturianas, Universidad de Oviedo, Oviedo, 1985.

Herculano, Alexandre, Portugaliae Monumenta Historica. Diplomata et Chartae, Academia das Ciências de Lisboa, Lisboa, 1868, fasc. 1.

Historia silense, Justo Pérez de Urbel y Atilano González Ruiz-Zorrilla (eds.), Consejo Superior de Investigaciones Científicas, Madrid, 1959.

IBn Hayyān, Crónica de los emires Alhakam I y 'Abdarrahmān II entre los años 796 y 847 (Almuqtabis II-I), Mahmud Ali Makki y Federico Corriente, Instituto de Estudios Islámicos y del Oriente Próximo, Zaragoza, 2001.

IBN Hayyān, Crónica del califa Abderramán III an-Násir entre los años 912 y 942 (Al-Muqtabis V), María Jesús Viguera Molins y Federico Corriente Córdoba (eds.), Anúbar, Zaragoza, 1981.

IBN 'IDARI, Histoire de l'Afrique et de l'Espagne intitulée Al Bayano'l-Mogrib, Imprimerie Orientale, Argel, 1904.

IBN AL-JAṬīB, Histoire de l'Espagne musulmane, Evariste Lévi-Provençal (ed.), Moncho, Rabat, 1934.

Libro del tumbo, Archivo Catedralicio de León, códice $n^{\circ} 11$.

Loscertales García de Valdeavellano, Pilar, Tumbos del Monasterio de Sobrado de los Monjes, Dirección General del Patrimonio Artístico y Cultural, Archivo Histórico Nacional, Madrid, 1976.

Lucas de Tuy, Chronicon Mundi, Emma Falque Rey (ed.), Brepols, Turnhout, 2003.

Mañueco Villalobos, Manuel, y Zurita Nieto, José, Documentos de la Iglesia Colegial de Santa María la Mayor (hoy Metropolitana) de Valladolid, Sociedad de Estudios Históricos Castellanos, Valladolid, 1917, vol. 1.

Palacio SÁnchez-IzQuierdo, María Luisa, Colección diplomática del monasterio de S. Zoilo de Carrión (siglos IX al XV), Tesis doctoral, Universidad Complutense de Madrid, Facultad de Geografía e Historia, Departamento de Ciencias y Técnicas Historiológicas, Madrid, 1988, vol. 2.

PAZ, Julián, "Donación del monasterio de San Cosme y San Damián en Simancas", Boletín de la Sociedad Castellana de Excursiones, 94 (1910), pp. 525-526.

Pérez, Ventura, Historia de la muy noble y muy leal ciudad de Valladolid, vol. 1, Biblioteca Nacional de España, MSS/19325.

Rodríguez de Diego, José Luis, Colección diplomática de Santa María de Aguilar de Campoo (852-1230), Junta de Castilla y León, Consejería de Cultura, Valladolid, 2004. SAmpiro, Sampiro. Su crónica y la monarquía leonesa en el siglo $X$, Justo Pérez de Urbel (ed.), CSIC, Madrid, 1952.

SÁEz SÁnchez, Emilio, Colección documental del Archivo de la Catedral de León (7751230), Centro de Estudios e Investigación "San Isidoro", Caja de Ahorros y Monte de Piedad, Archivo Histórico Diocesano, León, 1987, vol. 1, doc. 75. 
Serrano, Luciano, Cartulario de monasterio de Vega con documentos de San Pelayo y Vega de Oviedo, Junta para Ampliación de Estudios e Investigaciones Científicas, Centro de Estudios Históricos, Madrid, 1927.

AL-QALQAŠAndī, Șubḥ al-a šà fì șinā'at al-inšā, El Cairo, 1914.

AL-'UdRI, Fragmentos geográfico-históricos de Al-masālik ilà gamī al-mamalīk, 'Abd al'AzīzAl-Ahwānī (ed.), Instituto Egipcio de Estudios Islámicos de Madrid, Madrid, 1965.

\section{Estudios}

Aguilar Sebastián, Victoria, y Rodríguez Mediano, Fernando, "Antroponimia de origen árabe en la documentación leonesa (siglos VIII-XI)", El reino de León en la Alta Edad Media, Centro de Estudios e Investigación San Isidoro, León, 1994, t. 6, pp. 499-633. Aguirre Cano, Víctor Manuel, "Mahmud ben Abd al-Yabbar: un rebelde en el reino de Alfonso II de Asturias", Letras de Deusto, 129 (2010), pp. 121-245.

Aillet, Cyrille, "Introduction”, ¿Existe una identidad mozárabe? Historia, lengua y cultura de los cristianos de al-Andalus (siglos IX-XII), Cyrille Aillet, Mayte Penelas y Philippe Roisse (eds.), Casa de Velázquez, Madrid, 2008, pp. IX-XVI.

Aillet, Cyrille, "El monasterio de Lorvâo y los confines de la Beira (siglos IX-XII). Apuntes sobre la memoria histórica de un espacio de contacto", Studia historica. Historia medieval, 27 (2009), pp. 71-95.

Aillet, Cyrille, Les mozarabes. Christianisme, islamisation et arabisation en Péninsule Iberique (IX ${ }^{\mathrm{e}}-X I I^{\mathrm{e}}$ siècle), Casa de Velázquez, Madrid, 2010.

Almagro-Gorbea, Martín, "Los orígenes de Toletum y su topónimo campaniforme", Creer y entender. Homenaje a Ramón Gonzálvez Ruiz, Real Academia de Bellas Artes y Ciencias Históricas de Toledo, Toledo, 2014, vol. 1, pp. 145-158.

Almuiña Fernández, Celso, Personajes vallisoletanos. 6, El nombre de Valladolid, Pascual Martínez Sopena (coord.), El Norte de Castilla, Valladolid, 1996.

Alonso CoRTÉs, Narciso, "En torno a Valladolid", Castilla artística e histórica. Boletín de la Sociedad Castellana de Excursiones, 187 (1918), pp. 164-168, y 188, 189 y 190 (1918), pp. 184-190.

Alonso y Fernández de las Redondas, Dámaso, "B = V en la Península Hispánica", Obras completas, Gredos, Madrid, 1972, vol. 1, pp. 215-290.

Alonso GARCÍA, Amado, "La 'b' y la 'v"', De la pronunciación medieval a la moderna en español, Gredos, Madrid, 1967, vol. 1, pp. 21-61.

Álvarez Borge, Ignacio, Poder y relaciones sociales en Castilla en la Edad Media. Los territorios entre el Arlanzón y el Duero en los siglos X y XIV, Junta de Castilla y León, Valladolid, 1996.

Ariza Viguera, Manuel, Manual de fonología histórica del español, Editorial Síntesis, Madrid, 1989. 
Ariza Viguera, Manuel, Fonología y fonética históricas del español, Arco/Libros, Madrid, 2012.

Asín Palacios, Miguel, Contribución a la toponimia árabe de España, Consejo Superior de Investigaciones Científicas, Patronato Menéndez y Pelayo, Instituto Benito Arias Montano, Madrid-Granada, 1940.

BARrios GARCíA, Ángel, “Conquista y repoblación: el proceso de reconstrucción del poblamiento y el aumento demográfico”, en Ángel Barrios García (coord.), Historia de Ávila, Institución Gran Duque de Alba, Obra Cultural de la Caja de Ahorros de Ávila, Ávila, 2000, v. 2, pp- 227-270.

Bascuas López, Edelmiro, Hidronimia y léxico de origen paleoeuropeo en Galicia, Ediciós do Castro, Sada, 2006.

Belasko, Mikel, Diccionario etimológico de los nombres de los pueblos, villas y ciudades de Navarra, Pamiela, Pamplona, 1999.

Blanco González, Antonio, López-Sáez, José Antonio, Alba, Francisca, Abel, Daniel, y PÉrez, Sebastián, "Medieval landscapes in the Spanish Central System (450-1350): a palaeoenviromental and historical perspective", Journal of Medieval Iberian Studies, 7 (2015), 1, pp. 1-17.

Calvo Baeza, José María, Nombres de lugar españoles de origen árabe, Darek-Nyumba, Madrid, 1990.

CARvajal, Álvaro, y Martín Viso, Iñaki, "Historias regionales de la repoblación: los reyes asturleoneses y las "políticas de la tierra" en el oeste de la meseta del Duero", en Pablo de la Cruz Díaz Martínez, Fernando Luis Corral e Iñaki Martín Viso (coords.), El historiador y la sociedad. Homenaje al profesor José $M^{a}$ Minguez, Universidad de Salamanca, Salamanca, 2013, pp. 39-52.

Casado Quintanilla, Blas, "Melic (+960), presbítero, agricultor y ganadero: datos y conjeturas", Espacio, tiempo y forma, serie III, historia medieval, 22 (2009), pp. 47-64. Castro Toledo, Jonás, Alkamin: un lugar en la Tierra de Tordesillas. Estudio diplomático e histórico hasta su desaparición, Tesis de Licenciatura inédita, Universidad de Valladolid, Valladolid, 1971.

Celdrán, Pancracio, Diccionario de topónimos españoles y sus gentilicios, Espasa, Madrid, 2009.

Chavarría Arnau, Alexandra, "Romanos y visigodos en el valle del Duero (siglos V-VIII)", Lancia. Revista de prehistoria, arqueología e historia antigua del noroeste peninsular, 6 (2004-2005), pp. 187-204.

Chavarría Arnau, Alexandra, El final de las villae en Hispania (siglos IV-VII d.C.), Brepols, Turnhout, 2007.

Christys, Ann Rosemary, Christians in al-Andalus, 711-1000, Routledge, Richmond, 2002. 
Escalona Monge, Julio, "Comunidades, territorios y poder condal en la Castilla del Duero en el siglo X”, Studia histórica. Historia medieval, 18-19 (2000-2001), pp. 85-119.

Corriente, Federico, Árabe andalusí y lenguas romances, Mapfre, Madrid, 1992.

Estepa Díez, Carlos, Estructura social de la ciudad de León (siglos XI-XIII), Centro de Estudios e Investigación "San Isidoro", Archivo Histórico Diocesano, Caja de Ahorros y Monte de Piedad de León, León, 1977.

Fatás Cabeza, Guillermo, Caballero Zoreda, Luis, García Merino, Carmen, y Cepas Palanca, Adela, Tabula Imperii Romani. Hoja K-30: Madrid. Caesaraugusta-Clunia, Unión Académica Internacional, Madrid, 1993.

Fernández del Pulgar, Pedro, Libro segundo de la historia secular y eclesiástica de la ciudad de Palencia, Viuda de Francisco Nieto, Madrid, 1679(?).

Franco-SÁnchez, Francisco, "La toponimia árabe de los espacios viales y los espacios defensivos en la Península Ibérica", en Cristina Carvalho, Montserrat Planelles y Elena Sandakova (eds.), De la langue à l'expression: le parcours de l'expérience discursive. Hommage à Marina Aragón Cobo, Publicaciones de la Universidad de Alicante, Alicante, 2017, pp. 167-190.

Gómez RenAu, Mar, "La aljama de Valladolid: nuevas aportaciones", Anaquel de estudios árabes, 15 (2004), pp. 141-163.

Hernández Alonso, César, Nombre y renombre de Valladolid, Obra Cultural de la Caja de Ahorros Popular, Valladolid, 1986.

Нгтснсоск, Richard, Mozarabs in Medieval and Early Modern Spain. Identities and influences, Ashgate Publishing, Aldershot, 2008.

JIMÉNEZ RAYADO, Eduardo, "La construcción de la identidad a través del territorio en la Edad Media. El origen Bereber del nombre de Madrid", Medievalismo, 30 (2020), pp. 269-300.

Martín Montes, Miguel Ángel, El Alcázar Real de Valladolid, Fundación Municipal de Cultura, Valladolid, 1995.

Martín Montes, Miguel Ángel, y Moreda Blanco, Javier, "Aproximación a la génesis y desarrollo urbanístico de Valladolid durante la Plena Edad Media (siglos XI-XIII)", Codex Aquilarensis. Cuadernos de investigación del Monasterio de Santa María la Real, 15 (1999), pp. 153-186.

Martín Viso, Iñaki, Poblamiento y estructuras sociales en el norte de la Península Ibérica (siglos VI-XIII), Universidad de Salamanca, Salamanca, 2000.

MARTín VISO, Iñaki, "Una frontera casi invisible: los territorios al norte del Sistema Central en la Alta Edad Media (siglos VIII-XI)", Studia historica. Historia Medieval, 23 (2005), pp. 89-114.

Martín Viso, Iñaki, "Tumbas y sociedades locales en el centro de la Península Ibérica en la Alta Edad Media: el caso de la comarca de Riba Côa (Portugal)", Arqueología y territorio medieval, 14 (2007), pp. 21-47. 
MARTín Viso, Iñaki, "Espacios sin Estado: los territorios occidentales entre el Duero y el Sistema Central (siglos VIII-IX)", ¿Tiempos oscuros? Territorio y sociedad en el centro de la Península Ibérica (siglos VII-X), Sílex, Universidad de Salamanca, Madrid, Salamanca, 2009, pp. 107-135.

MARTín VISO, Iñaki, "Un mundo en transformación: los espacios rurales en la Hispania post-romana (siglos V-VII)”, Visigodos y omeyas: el territorio, Luis Caballero Zoreda, Pedro Mateos Cruz y Tomás Cordero Ruiz (coords.), CSIC, Junta de Extremadura, Mérida, 2012, pp. 31-63.

MARTín Viso, Iñaki, "Paisajes sagrados, paisajes eclesiásticos: de la necrópolis a la parroquia en el centro de la Península Ibérica”, Reti medievali revista, 13 (2012), vol. 2, pp. 3-45.

MARTín VISO, Iñaki, “¿Datar tumbas o datar procesos? A vueltas con la cronología de las tumbas excavadas en roca en la Península Ibérica”, Debates de arqueología medieval, 4 (2014), pp. 29-65.

Martínez Salazar, Andrés, "Sobre etimologías, Valladolid", Castilla artística e histórica. Boletín de la Sociedad Castellana de Excursiones, 185 (1918), pp. 114-120.

Medina López, Historia de la lengua española. I, Español medieval, Arco/Libros, Madrid, 2018.

MENÉNDEZ PidAl, Ramón, "Sobre el sustrato mediterráneo occidental”, Ampurias. Revista de arqueología, prehistoria y etnografía, 2 (1940), pp. 3-16.

Mínguez Fernández, José María, La España de los siglos VI al XIII. Guerra, expansión y transformaciones. En busca de una frágil unidad, Nerea, San Sebastián, 2008.

Mínguez Fernández, José María, "Innovación y pervivencia en la colonización del valle del Duero", en VV.AA., Despoblación y colonización del valle del Duero, siglos VIII-XX. IV Congreso de Estudios Medievales, Fundación Sánchez-Albornoz, Ávila, 1995, pp. 45-79.

Mínguez Fernández, José María, "La repoblación de los territorios salmantinos", en José María Mínguez Fernández (coord.) y José Luis Martín Rodríguez (dir.), Historia de Salamanca. II, Edad Media, Centro de Estudios Salmantinos, Salamanca, 1997, pp. 13-74.

Mínguez Fernández, José María, "La despoblación del Duero: un tema a debate", Acta historica et archaeologica mediaevalia, 22 (2001), pp. 67-80.

Mínguez Fernández, José María, "La frontera del Sistema Central: una realidad difusa”, en Gregorio del Ser Quijano e Iñaki Martín Viso (eds.), Espacios de poder y formas sociales en la Edad Media. Estudios dedicados a Ángel Barrios, Universidad de Salamanca, Salamanca, 2007, pp. 203-218.

Montenegro Duque, Ángel, “Origen céltico del nombre y lugar de Valladolid”, Boletín del Seminario de Estudios de Arte y Arqueología, 13 (1946-1947), pp. 37-56. 
Montenegro Duque, Ángel, "El origen céltico del nombre de Valladolid y la difusión de la raíz "tol" en la toponimia y hablas hispanas", Historia de Valladolid. I, Prehistoria y Edad Antigua, Ateneo de Valladolid, Valladolid, 1977, pp. 29-67.

Montenegro Duque, Ángel, "El origen céltico del topónimo Valladolid. Vallistolitum $>$ Valladolid y Vallis-tolitanus $>$ Vallisoletano. (Nuevos argumentos y planteamientos de la cuestión)", Minerva. Revista de filología clásica, 15 (2001), pp. 11-37.

Moreno Gallo, Isaac, "Vía romana de Sasamón a Villalazán", Vias romanas de Castilla y León, 2011-2017. http://www.viasromanas.net/pdf/20_Via_romana_Sasamon_a_Villalazan.pdf [31/12/2019]

Moro GutiÉrRez, Lourdes, "Estudio etnográfico de Zaratán", Revista de folklore, 144 (1992), pp. 204-216.

Moscoso García, Francisco, Esbozo gramatical del árabe marroquí, Ediciones de la Universidad de Castilla-La Mancha, Cuenca, 2004.

Moxó, Salvador de, Repoblación y sociedad en la España cristiana medieval, Ediciones Rialp, Madrid, 1979.

Ouiver Asín, Jaime, Historia del nombre “Madrid”, Instituto Miguel Asín, Madrid, 1959.

Oliver Asín, Jaime, En torno a los orígenes de Castilla. Su toponimia en relación con los árabes y los bereberes, Real Academia de la Historia, Madrid, 1974.

Ortega y Rubio, Juan, Historia de Valladolid, Imprenta y Librería Nacional y Extranjera de Hijos de Rodríguez, Valladolid, 1881.

Palol, Pedro de, y Wattenberg, Federico, Carta arqueológica de España, Valladolid, Diputación Provincial de Valladolid, Servicio de Investigaciones Arqueológicas, Valladolid, 1974.

Pastor Díaz de Garayo, Ernesto, Castilla en el tránsito de la Antigüedad al feudalismo. Poblamiento, poder político y estructura social del Arlanza al Duero (siglos VII-XII), Junta de Castilla y León, Valladolid, 1996.

Pérez Marinas, Iván, Sansón de Córdoba: vida y pensamiento. Comentario de las obras de un intelectual cristiano-andalusi del siglo IX, Ediciones La Ergástula, Madrid, 2012. Pérez Marinas, Iván, Tierra de nadie. Sociedad y poblamiento entre el Duero y el Sistema Central (siglos VIII-XI), Mablaz, Madrid, 2017.

Quintana López, Javier, "El estado actual del yacimiento de Villa de Prado: últimas intervenciones y retos para su conservación futura", Villa de Prado, un asentamiento romano en la ciudad de Valladolid. Primeras jornadas de "Patrimonio y ciudad Villa de Prado", Arturo Balado Pachón (coord.), Ayuntamiento de Valladolid, Valladolid, 2016, pp. 91-114.

Quilis Morales, Antonio, Fonética histórica y fonología diacrónica, UNED, Madrid, 2005.

Reglero de la Fuente, Carlos Manuel, Espacio y poder en la Castilla medieval. Los Montes de Torozos (siglos X-XIV), Diputación Provincial de Valladolid, Valladolid, 1994. 
Represa Rodríguez, Amando, "Origen y desarrollo urbano del Valladolid medieval (siglos X-XIII)", Historia de Valladolid. II, Valladolid medieval, Ateneo de Valladolid, Valladolid, 1980, pp. 65-86.

Reyes Téllez, Francisco, Población y sociedad en el valle del Duero, Duratón y Riaza en la Alta Edad Media, siglos VI a XI: aspectos arqueológicos, Tesis Doctoral inédita, Universidad Complutense de Madrid, Madrid, 1991.

Riguera Montero, José María, “Vallisoletanos o valisoletanos?”, Castilla artística e histórica. Boletín de la Sociedad Castellana de Excursiones, 186 (1918), pp. 129-132. Ruiz Asencio, José Manuel, "La provincia de Valladolid en la Alta Edad Media (siglos VIII-XI)", Historia de Valladolid. II, Valladolid medieval, Ateneo de Valladolid, Valladolid, 1980, pp. 9-63.

Sánchez-Albornoz, Claudio, El obispado de Simancas, Imprenta de la Librería y Casa Editorial Hernando, Madrid, 1925.

SÁnCheZ-Albornoz, Claudio, La España cristiana de los siglos VIII al XI, Espasa-Calpe, Madrid, 1980, vol. 1.

SÁnchez Simón, Margarita, "El yacimiento "Villa romana de Prado", Villa de Prado, un asentamiento romano en la ciudad de Valladolid. Primeras jornadas de "Patrimonio y ciudad Villa de Prado”, Arturo Balado Pachón (coord.), Ayuntamiento de Valladolid, Valladolid, 2016, pp. 63-90.

Sangrador Vítores, Matías, Historia de la muy noble y leal ciudad de Valladolid, desde su más remota antigüedad hasta la muerte de Fernando VII, Imprenta de D. M. Aparicio, Valladolid, 1851.

Tovar, Antonio, "El nombre de celtas", Revista de la Universidad Complutense, 109 (1977), pp. 163-178.

Untermann, Jürgen, Elementos de un atlas antroponímico de la Hispania antigua, Consejo Superior de Investigaciones Científicas, Universidad de Madrid, Madrid, 1965.

Urueña Paredes, Juan Carlos, Rincones con fantasma. Un paseo por el Valladolid desaparecido, Ayuntamiento de Valladolid, Valladolid, 2006.

VAcA Lorenzo, Ángel, "El obispado de Palencia desde sus orígenes hasta su definitiva restauración en el siglo XI”, Hispania sacra, 105 (2000), pp. 21-70.

VAllvé Bermejo, Joaquín, “Toponimia de España y Portugal. Las lenguas hispánicas y su reflejo en las fuentes árabes”, Boletín de la Real Academia de la Historia, 193, 2 (1996), pp. 197- 238.

Vieira, Marina Afonso, Alto Paiva. Povoamento nas épocas romanas e alto-medieval, Instituto Português de Arquelogia, Lisboa, 2004.

Viguera Molins, María Jesús, "La Ruta de la Plata y sus territorios en fuentes textuales árabes", La Vía de la Plata y otros estudios sobre Extremadura: XIV Jornada de Historia de Fuente de Cantos, Asociación Cultural de Lucerna, Fuente de Cantos, 2013, pp. 41-65. 
Viguera Molins, María Jesús, "Una andalusí en Galicia y sus cuatro "transgresiones", Estudios de frontera 8. Mujeres y fronteras, en Francisco Toro Ceballos y José Rodríguez Molina (coords.), Diputación de Jaén, Jaén, 2011, pp. 497-505.

Villar García, Luis Miguel, La Extremadura castellano-leonesa. Guerreros, clérigos y campesinos (711-1252), Junta de Castilla y León, Valladolid, 1986.

Villar Liébana, Francisco, "Las vocales /o/ y /u/ de la toponimia prerromana hispana", Veleia, 10 (1993), pp. 179-190.

Villar LiéBana, Francisco, “Talabara, Talavera, Toledo”, en Ignacio J. Adiego, Jaime Siles y Javier Velaza (eds.), Studia palaeohispanica et indogermanica J. Untermann ab amicis hispanicis oblata, Publicacions Universitat de Barcelona, Barcelona, 1993, pp. 287-295.

Wickнам, Chris, Una historia nueva de la Alta Edad Media. Europa y el mundo mediterráneo, 400-800, Crítica, Barcelona, 2009. 